FD-A153 162

THE UTILIZATION OF NAYY PEOPLE-RELATED ROT\&E (RESEARCH

$1 / 1$ DEVELOPMENT TEST $A$. . (U) BIOTECHNOLOGY INC FALLS CHURCH $\checkmark A$ C 5 LEHIS ET RL. MAY 81 OPNAY-NOTE-3905-4

UNCLASSIFIED N66001-80-C-6456 F/G $15 / 5$

NL
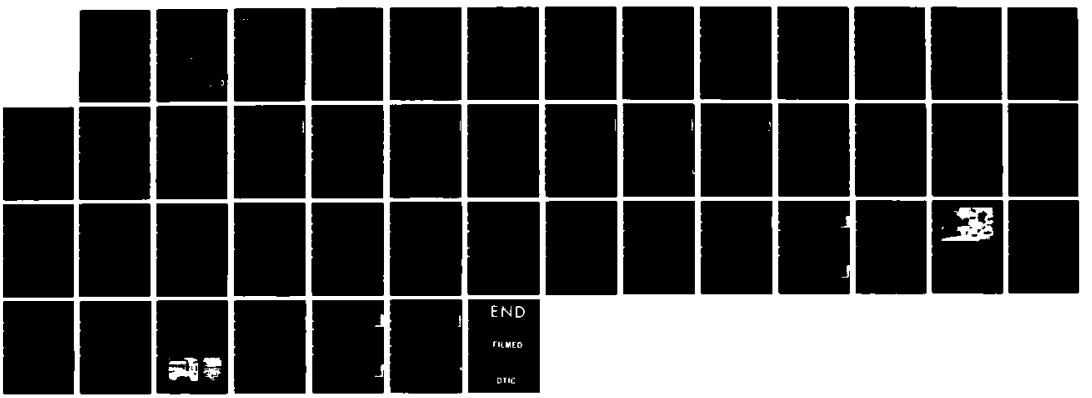


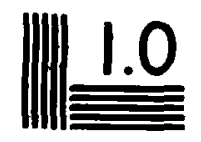

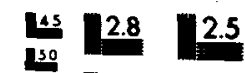

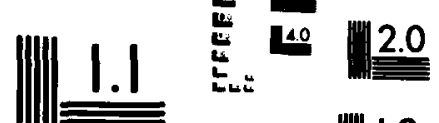

$11 \|$ 
ON

ช

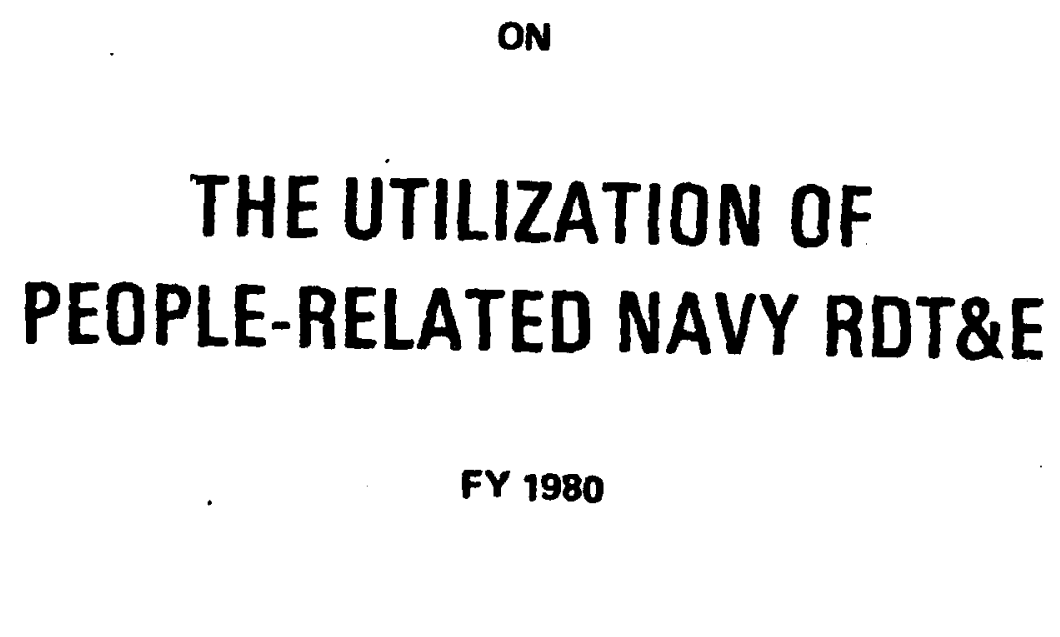

May 1981

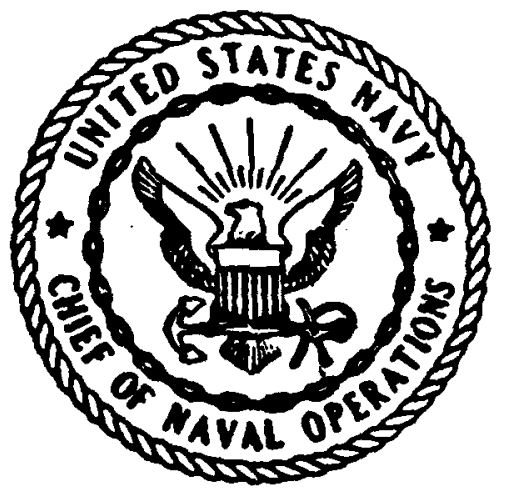

2

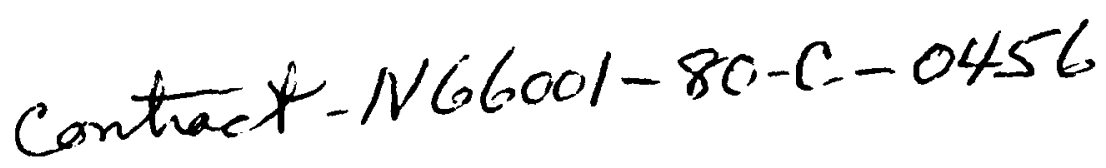

Asembled by

Nowy Personnol Reseaveh and Dowelopment Conter

San Diego, California 92152

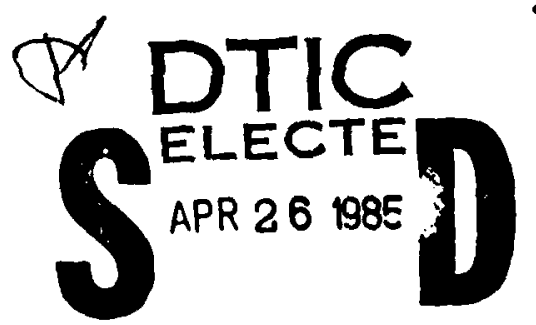

D

APPROVED FOR PUBLIC AELEASE: DISTRIBUTION YQLPITEO

$3 \pm \sqrt{3}$ 


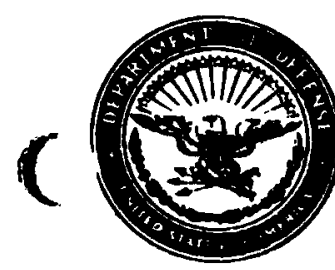

\section{DEPARTMENT OF THE NAVY}

OFFICE OF THE CHIEF OF NAVAL OPERATIONS

WASHINGTON. DC 20350

Canc: Oct 82

INAETY REFER TO

OPNATH VYTER 3905

Ser $987 / 362129$

OPNAV NOTICE 3905

OCT 161991

From: Chief of Naval Operations

Subj: Fourth Annual Report on the Utilization of People-Related RDT\&E

Ref: (a) UNDSECNAV Memo of 26 September 1978, Subj: Navy Manpower, Personnel and Training Research, Development and studies (NOTAL)

(b) General Accounting office Report FPCD 77-43 of 22 . April 1977 (NOTAL)

Encl: (1) Fourth Annual Report on the Utilization of PeopleRelated Navy RDT\&E

1. Purpose. To promulgate the Fourth Annual Report on the utilization of People - Related Navy RDT\&E (enclosure (1)) and forward it for information and appropriate action. This report contains examples of the use of this R\&D. It is a principal means whereby the Navy complies with the recommendations of references (a) and (b) that utilization be encouraged,-.that communication between the user and researcher be improved, and that utilization of this R\&D be tracked.

\section{Action}

a. Addressees are requested to review enclosure (1) to identify any of the following:

(1) RDT\&E that they have used but has not been reported in enclosure (1) or any of its predecessors.

(2) Completed RDT\& that might be useful in activities under their cognizance.

(3) RDTEE near completion that they should monitor to use when completed.

b. Any previously unreported instances of utilization should be reported to:

Commanding officer

Navy Personnel Research and Development Center Code 303

San Diego, CA 92125 
OPNAVNOTE 3905

OCT 161981

c. Addressees desiring assistance in using completed RDT\&E or in monitoring potentially useful R\&D should direct inquiries to the appropriate R\&D organizations as listed in enclosure (1).

d. Request appropriate action to be completed by 31 may 1982. Negative reports are not required.

3. Report. Symbol OPNAV 3905-1 has been assigned to the requirement contained in paragraph 2. This information will be requested yearly by notice.

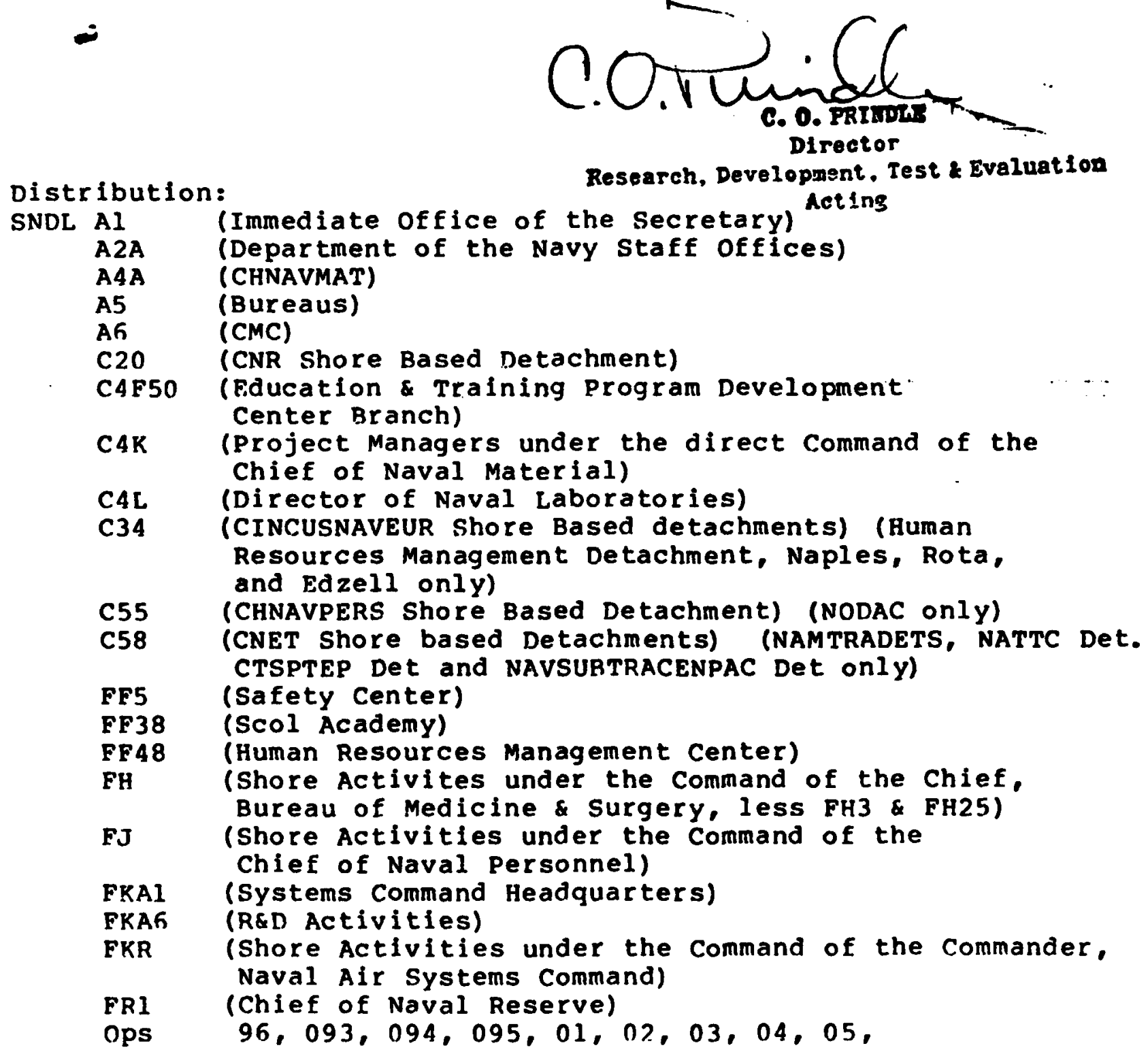




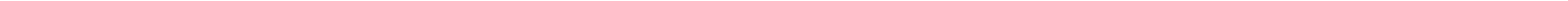




\section{THE UTILIZATION OF PEOPLE-RELATED NAVY RDT\&E}




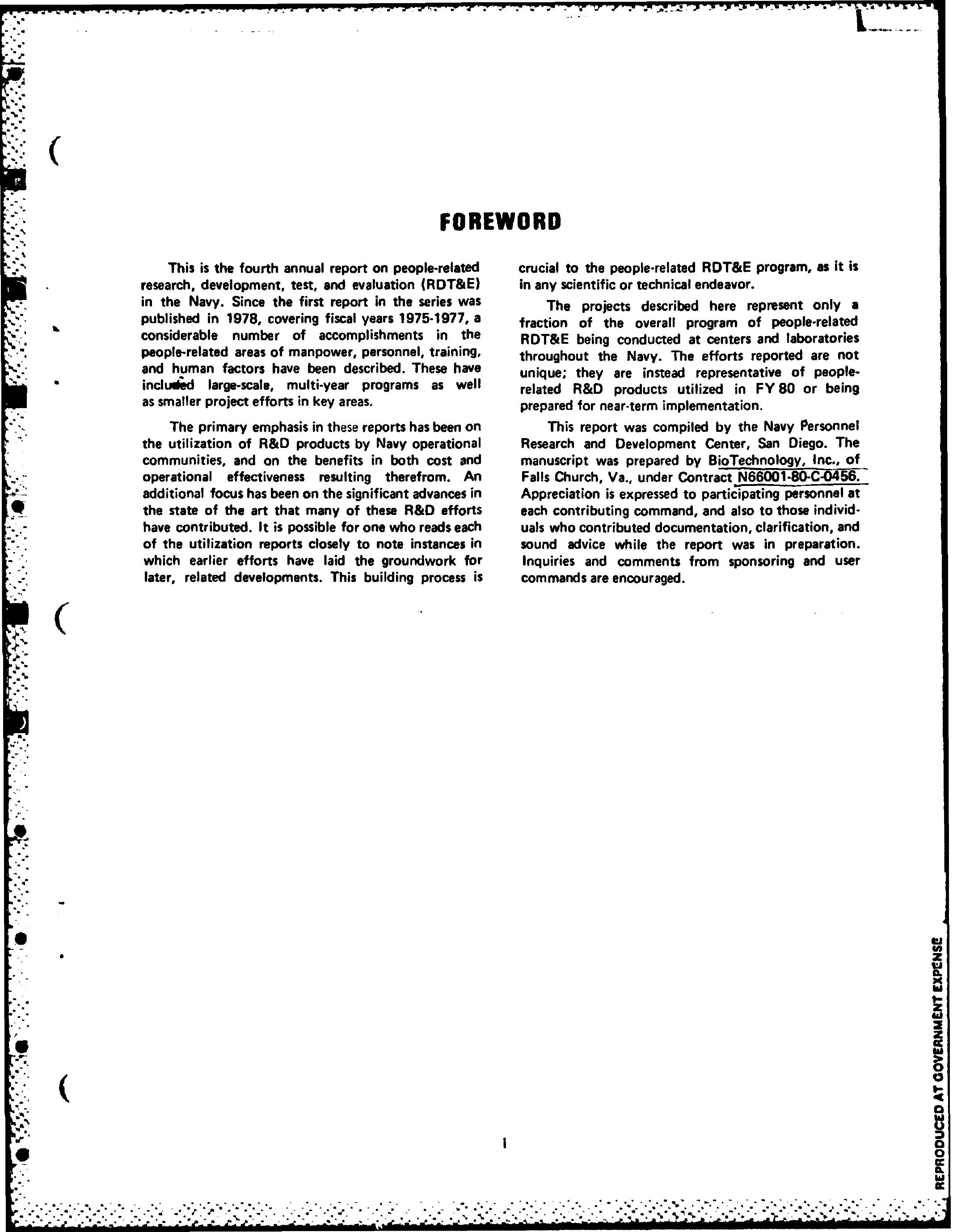




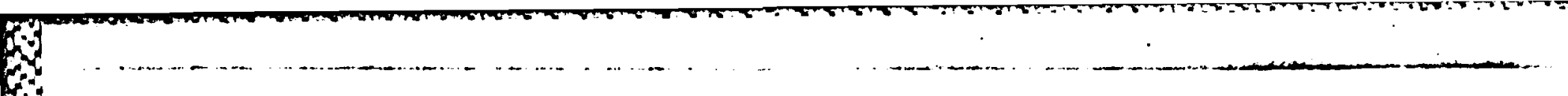

\section{CONTENTS}

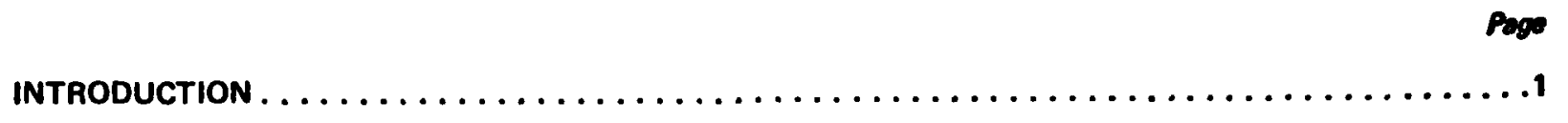

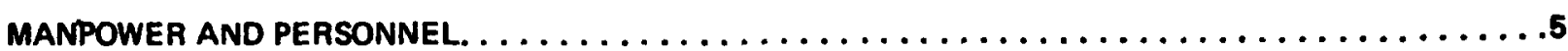

Reding the Cost of Job Analysis Surveys . . . . . . . . . . . . . . . . . . . . . .

Identifying Impediments to Navy Industrial Productivity . . . . . . . . . . . . . . . . .

Improving the Management of Recruiting Resources $\ldots \ldots \ldots \ldots \ldots \ldots \ldots \ldots$

Computerized Navy Recruiting, Assignment, Counseling, and Testing . . . . . . . . . . . . . . 10

Billet Cost Models . . . . . . . . . . . . . . . . . . . . . . . . . . . . . . . . 12

Tracking Gender-Integrated Crews . . . . . . . . . . . . . . . . . . . . . . 13

Performance-Based Incentive System for Greater Productivity . . . . . . . . . . . . . . . . . 14

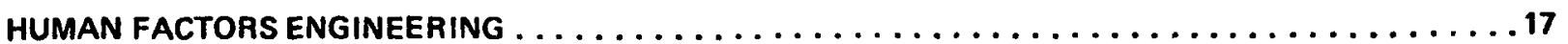

Planning for the Implementation of NTIPS. . . . . . . . . . . . . . . . . . . . . . . . 19

Improving Air-to-Air Target Sighting. . . . . . . . . . . . . . . . . . . . . . . . 21

Designing Computerized Decision Aids for Airborne Systems. . . . . . . . . . . . . . . . . . 23

EDUCATION AND TRAINING. . . . . . . . . . . . . . . . . . . . . . . . . 27

Shipboard Training for the Shipboard Environment . . . . . . . . . . . . . . . . . . . . . 29

Instructional Quality Inventory: Quality Control for Courseware . . . . . . . . . . . . . . . . 30

ECCM Training Through Microprocessors. . . . . . . . . . . . . . . . . . . . . . . 32

Implementing the "JOBs" Program . . . . . . . . . . . . . . . . . . . . . . .

SIMUlation AND tRAINING DEVICES . . . . . . . . . . . . . . . . . . . . . . 35

Cost-Effective Avionics Maintenance Trainers. . . . . . . . . . . . . . . . . . . . . . 37

Simulation for Advanced Submarine Tactical Training . . . . . . . . . . . . . . . . . . . 39

Low-Cost Part-Task Trainers . . . . . . . . . . . . . . . . . . . . . . . . . . . .4t

NiRDC Praticipa Tion 


\section{INTRODUCTION}

Like the preceding reports in the series, this fourth annual utilization report describes Navy "people-related" research, development, test, and evaluation (RDT\&E) efforts that have been utilized by operational commands or have contributed to the technology base that supports present and future operational needs of the Navy. Such efforts in all Servicus are funded under the Training and Personnel Systems Technology (TPST) program within the Office of the Under Secretary of Defense for Research and Engineering. Taken together, they comprise about 4 percent of the DoD's overall Science and Technology (S\&T) program. The remaining 96 percent is devoted primarily to weapons and systems R\&D.

The TPST program is concerned on a broad scale with issues of manpower, personnel, and training. These issues are divided into four general categories (which also form the organizational framework for this report):

- Manpower and Personnel

- Human Factors Engineering

- Education and Training

- Simulation and Training Devices.

With changes in the policy and economic environ. ments, in the structure of the operational forces, and in the demographic and sociological makeup of the nation as a whole, particular areas of effort at times assume greater relative importance. Each fiscal year a different group of specific objectives is targeted for special R\&D attention. In FY 80, the high-priority thrusts were for R\&D directed at:

- Maintaining performance levels

- Predicting the effectiveness of personnel

- Developing lower-cost training that is more effective and more available

- Building the technology base to meet future needs.

This report is one vehicle by which the Navy communicates its progress toward those goals and its success in developing and implementing specific solutions to problems the service faces in the acquisition, training, utilization, and management of personnel. The report is intended to increase the utilization of newly developed training and personnel systems technology, and also to foster greater Navy-wide and interservice coordination of efforts in people-related
RDT\&E. In each project summary, emphasis is placed on (1) the operational need that generated the effort, (2) the way in which the research products or results were (or will be) utilized, and (3) the actual or potential "payoff" to be gained. Each project summary also includes a section which identifies the performing activity and sources of funding for the project. Most carry Program 6 R\&D funding, and a diagram is provided with each summary illustrating the evolution of the effort through the various funding levets. These Program Element levels correspond generally to successive levels of development, as follows:

- 6.1: Basic Research - Scientific study and experimentation directed toward increasing knowledge in fields related to long-term national security needs.

- 6.2: Exploratory Development - Efforts directed toward the solution of specific military problems, short of major development.

- 6.3: Advanced Development - Develinoment of systems or system components for experimental or operational test. A primary objective is proof of design concepts.

- 6.4: Engineering Development - Design, fabrication, and testing of full-scale systems for operational application.

\section{The Need for People-Related ADT\&E}

\section{The Personnel-Hardware Imbalance}

Previous utilization reports have described the rapid emergence in recent years of a situation in which military hardware systems have gotten "out of sync" with the capabilities of the personnel who operate and maintain them. With the introduction of high-technology weapons systems, beginning in the air in the 1950s and extending to land and sea platforms from the 1960s on, a gap appeared between the demands these systems place on operators and main. tainers, and the ability of the personnel and training systems to adequately meet those demands. In the post-Vietnam era the drive toward modernization has increased the rate at which new and more complex weapons systems are introduced, serving to further widen the personnel-hardware gap.

\section{Attracting Qualified Recruits}

Beginning in 1972, with the advent of the All.Vol. unteer Force, a new factor emerged as a decline in the 
average aptitudes of enlistees began to be seen. A fall-off in the compensation of military personnel relative to wages in the private sector made the services less attractive to the more highly qualified potential recruits. This trend has been worsened by inflation in each succeeding year. Recruiting has become more difficult. In FY 79, for the first time since the end of conscription, all four of the services failed to achieve their recruiting objective; the DoD fell short of its recruitment goals by an average 7 percent.

To add to the difficulty of acquiring capable personnel, the year 1979 saw the beginning of a decline in the size of the eligible manpower pool - a decline that will continue at least through 1995. Whereas in 1980 roughly one out of 24 military eligible young men was needed to meet military manning requirinents, the projected requirement for $1990-92$ is on the order of one in thres.

The effects of this decline are aiready being felt. Despite creative tactics that are being pursued in every Service to lighten its impact (greater utilization of women, lowering of qualification standards, guaranteed training and assignment, enlistment bonuses, etc.), the Congressional Budget Office has estimated that the 1985 shortfall may be as much as 15 percent.

The difficulty in recruiting high-aptitude personnel takes on particular significance in the Navy in view of its problems with the retention of highly trained and experienced personnel - what Chief of Naval Operations ADM Thomas Hayward has referred to as "a hemorrhage of talent." According to the 1980 report of the House Armed Services Committee, last year the Navy had 20,000 fewer experienced petty officers than it required, with fully 20 percent of its ships operating under serious personnel deficiencies. These people are needed to man and maintain complex systems. And they are precisely the kinds of people who are the most difficult to replace in today's recruiting climate.

\section{The Importance of People-Related RDT\&E}

These problems have their ultimate impact in our readiness to fight a war. The net effect is that, although we are fielding technically superior systems, often they are not adequately manned, maintained, or supported. Because Soviet manpower exceeds our own in num. bers, we rely on our technological edge to maintain parity. It is critical that our advanced aircraft, ships, ordnance, and other systems perform as designed.

They cannot do so without adequate attention to the reliability of the system's human component. According to the Comptroller General's Report to the Congress, dated 29 January 1981, "human errors account for at least $\mathbf{5 0}$ percent of the failures of major systems." The report concludes that:

\begin{abstract}
'Weapon system designs have been dictating manpower requirements. What is needed is a continuing interface between the system designers and the manpower planners with manpower requirements influencing system design and vice versa." (p. 33)
\end{abstract}

"Essentially," as the Principal Deputy Under Secretary of Defense for Research and Engineering observed in an address in May 1980, "we design for maximum performance rather than to the skills that we get." This overemphasis on performance goals at the expense of long-term awnership considerutions such as operability and maintainability leads to high costs and excessive downtime. The need to incorporate manpower realities into the design of hardware will increase as the Navy continues to introduce sophisticated new systems such as the AEGIS guided misaile cruiser (CG 47).

People-related research can supply much of the information needed by system planners and designers. Previous utilization reports have described the development of personnel planning data sources that make it possible to forecast future manpower availability and personnel skill levels. This issue reports the development of billet cost models that allow life-cycle manpower costs of a system to be estimated in the design stage. Also reported are ways to maximize the effectiveness of recruiting and recruiting resources management on a nationwide basis.

It is possible to increase human reliability through innovative skills training - especially training focused on the particular requirements of the job. The JOBS program described in this report has that objective, as does the shipboard training program whose development is reported here. New sinulations for training are also presented. Simulators can provide highly effective and realistic training at a lower cost than operational equipment, and with much greater frequency of training opportunity than at-sea maneuvers or actual flight offer.

Better-designed training materials and betterquality training courses can bring higher return on the training dollar, increasing student skills and knowledge while reducing training time. The Instructional Quality Inventory, implemented in FY 80 at all Navy Instructional Program Development centers, will ensure that courseware developed by and for the Navy meets high standards of quality. The NTIPS program, now under advanced development, will provide a systematic means of generating technical information (such as technical manuals and job aids) for use on the job. Ease of use, high applicability to user needs, and ability to update are the hallmarks of NTIPS-produced materials. 


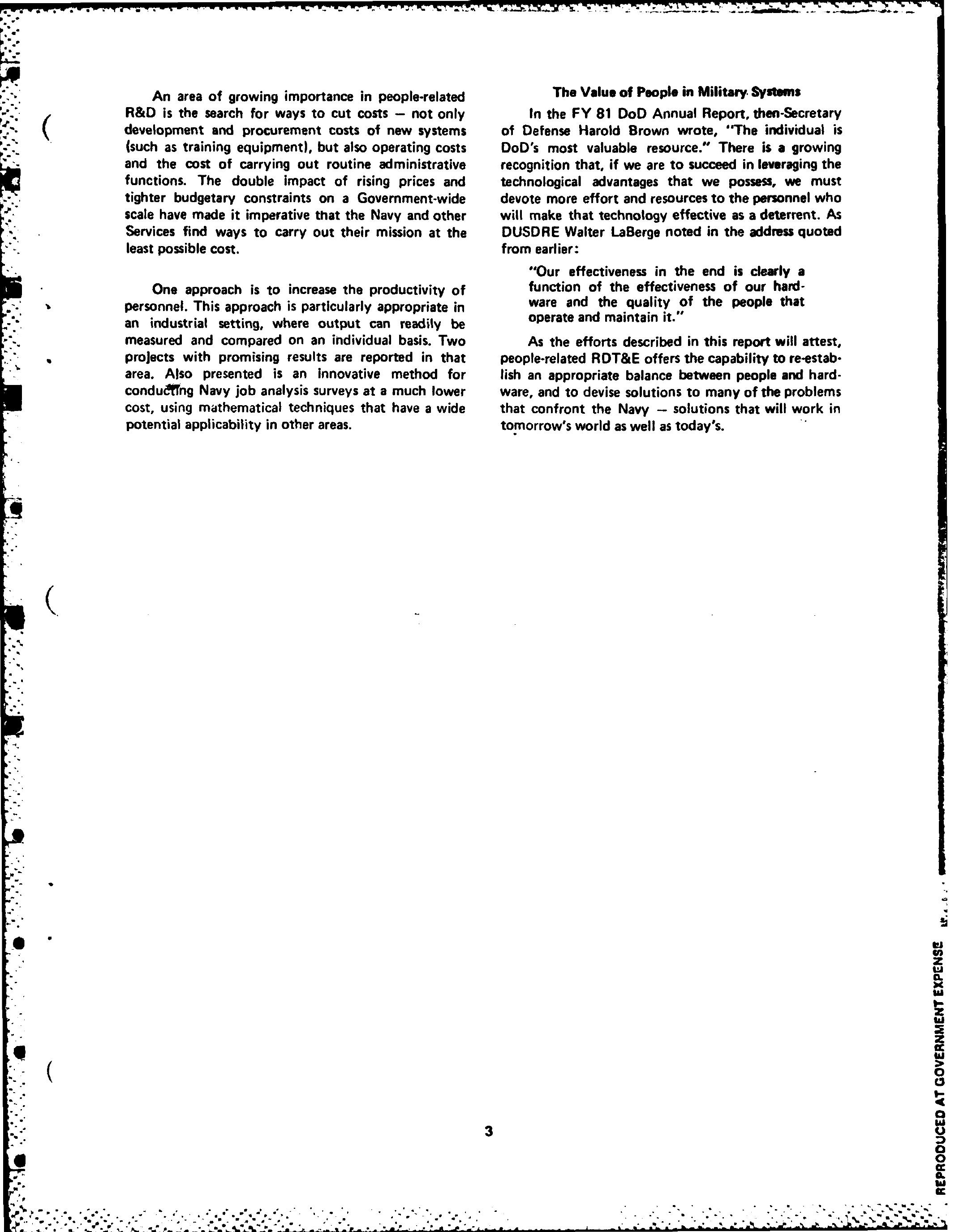




\section{MANPOWER AND PERSONNEL}

\section{DoD defines this area of People-Related RDT\&E as follows:}

"Development of techniques/methods for utilizing available personnel resources through improved selection; job assignment, organizational analysis and management techniques to meet combat-available and projected force needs."

The Navy must continually improve its manpower and personnel processes. These processes include: estimating life-cycle manpower requirements; developing more effective procedures for acquiring and classifying personnel; increasing productivity; and maintaining management capability to respond and adapt effectively to a changing force structure. A major focus at the present time is on finding ways to increase productivity and optimize the use of personnel resources while reducing or restraining costs.

Projects in this category include:

- Reducing the Cost of Job Analysis Surveys

- Identifying Impediments to Navy Industrial Productivity

- Improving the Management of Recruiting Resources

- Computerized Navy Recruiting, Assignment, Counseling, and Testing

- Billet Cost Models

- Tracking Gender-Integrated Crews

- Performance-Based Incentive System for Greater Productivity 


\section{REDUCING THE COST OF JOB ANALYSIS SURVEYS}

\section{Need}

The military services periodically collect job information by administering task inventories (structured work-analysis questionnaires) to large samples of their enlisted personnel. Since 1960, more than 800,000 job incumbents in the military services have completed inventories often containing as many as 1000 items. This is valuable and necessary information. The various services use it to specify occupational standards, to validate training curricula against the actual requirements of the job, and to structure occupational specialties. But surveying large numbers of job incumbents, and with lengthy questionnaires, places heavy fime demands on operating units and also results in high data processing costs.

In the Navy, the organization that develops and conducts these surveys is the Navy Occupational Development and Analysis Center (NODAC). NODAC requested that the Navy Personnel Research and Development Center (NPRDC) investigate ways to minimize the time required and to reduce costs while maintaining reliability in the data.

\section{Performing Activity and Program Element}

This project was conducted by the Navy Personnel Research and Development Center under the sponsorship of the Navy Occupational Development and Analysis Center. Funding was provided under Program Element 62763N. Program dynamics in support of this effort are depicted in the following diagram.

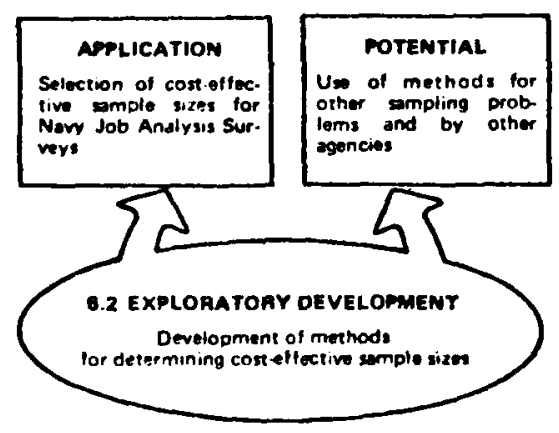

\section{Approach and Results}

The approach that NPRDC took was to develop techniques for identifying ideal sample sizes, i.e., the smallest number of subjects that could be surveyed while still producing reliable data. Ordinary statistical techniques could not be used. Due to an inability to obtain truly random samples of job incumbents, the researchers found that theoretical formulae for deter. mining sample size are not applicable for surveying personnel on board ship. Uncontrollable factors such as unscheduled ship deployment and personnel on leave require that data be collected from available (not randomly selected) job incumbents. Existing samples consisting of over 8,500 job incumbents who had completed task inventories were systematically reduced in size, and the progressive impact on the reliability of the data was evaluated. The figure shows the results. It was found that, in this particular application, the same high level of reliability is produced for samples of $\mathbf{8 0}$ as for samples of over $\mathbf{4 0 0}$ job incumbents (see Curve 1). When even more strict criteria of reliability were applied (see Curve 2), the break point occurred with a sample size of 250 ; above that number only minimum gains in reliability can be achieved.

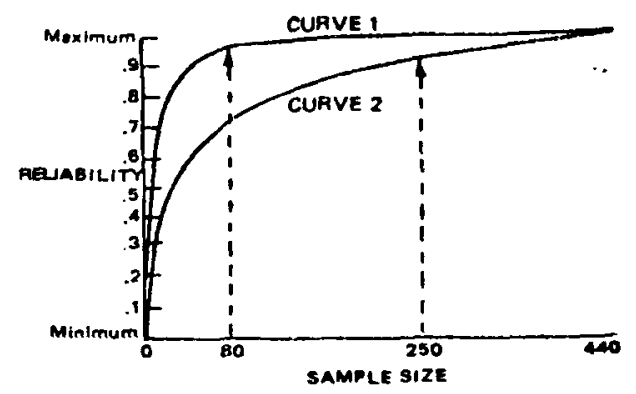

Impact of Sample Sire on Reliability

Graphs more detailed than the one presented here were developed to enable NODAC management to select cost-effectiv? jampling strategies by balancing gains in reliability against increased costs of data collection and analysis. In many cases, it has been determined that a reduction of 50 percent in existing job survey sample sizes could be accomplished with minimal effect on the reliability of the data.

\section{Utilization/Technology Base Advance}

Existing NODAC sampling procedures have been changed in accordance with the findings of this project. NPRDC has conducted workshops at NODAC and is providing ongoing consultation on sampling strategy. The results of the project were presented at the 1978 Military Testing Association Conference, and in NPRDC TR 80-28.

\section{Payoff/Potential}

The use of reduced sample sizes as recommended by the project's findings will result in an estimated savings of over 52,000 personnel work hours for every Navy job analysis survey cycle la cycle is completed every 4 to 5 years). In addition, savings of up to 50 percent for certain computer processing costs will be realized. The potential exists for applying the methods developed in this project to the designing of sampling strategies for other types of surveys, not only within the Navy but also in other military and govern. mental agencies. 


\section{IDENTIFYING IMPEDIMENTS TO NAVY INDUSTRIAL PRODUCTIVITY}

\section{Need}

There is increasing concern over the decline in industrial productivity in the United States. The Navy shares this concern and is paying particular attention to productivity issues within its own industrial community. Although in the past most productivity increases have been the result of innovations in hard technology (primarily in the form of automation), personnel systems that emphasize productivity are currently a focus of much interest. One aspect of personnel productivity research that has not received a great deal of attention is the need to identify and remove impediments (barriers) to productivity in the working environment.

\section{Performing Activity and Program Element}

This effort was carried out by NPRDC at the request of the Chief of Naval Material. The project was funded with reimbursable money, using a methodology originally provided under Program Element 62763N. Program dynamics in support of this effort are depicted in the following diagram.

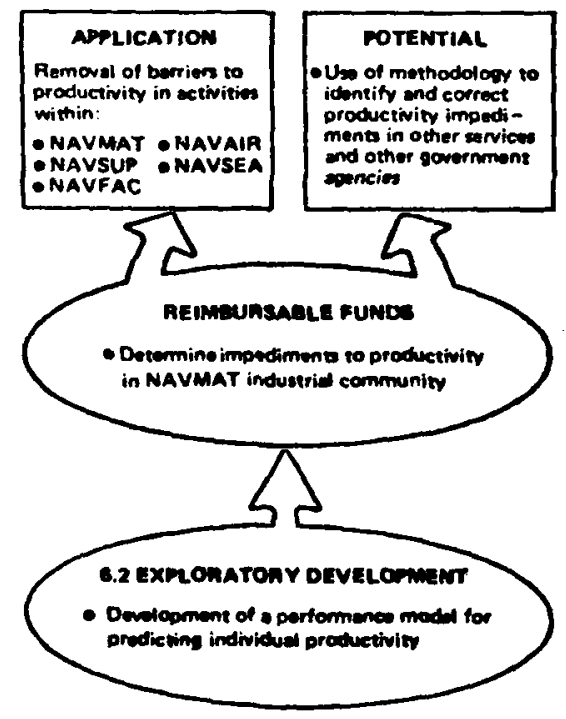

Approach and Results

Five Navy Material Command (NAVMAT) field activities were selected as being representative of the major types of organizations in the Navy's industrial community. These included a shipyard, a weapons station, a supply center, a public works center, and an air rework facility.

A methodology was established for identifying impediments to productivity in these facilities. It consisted of a combination of one-on-one interviews, group interviews, and questionnaires, conducted with or administered to workers as well as supervisory and management personnel. This survey program was carried out at each of the five facilities and the findings were reviewed and classified into several categories. Impediments that were classified as being under the control of local management were turned over to the respective activities for further assessment and action; those classified as being beyond local control were documented and pursued in greater depth through interviews at organizational levels above the field commands. In addition, researchers contacted management personnel at another command within each activity type (e.g., shipyard, supply center) to determine whether identified impediments were also seen as problems at other locations.

Those impediments that were common to more than one activity and were not under local control were presented in a briefing to commanders of the following organizations: Naval Supply Systems Command, Naval Facilities Engineering Command, Naval Air Systems Command, Naval Sea Systems Command, and, in addition, the Chief of Naval Material. These items can be divided roughly into two main categories: (1) pay/personnel-related issues and (2) material/equipment support and coordination. Items related to the pay/personnel issue included: GSWG pay inversion, difficulties in establishing position classifications, timeliness with which positions are staffed, abuses of pay continuation for traumatic injury, delays in getting results of National Agency Check and Inquiries (NACls) for personnel, and promotions based in part on supervisor appraisal. Items related to material/equipment support and coordination included: lack of support in the acquisition of supplies, material, and new equipment; the general lack and inadequacy of automated data processing (ADP) equipment; erratic workload; poor coordination of instructions; and lack of work coordination.

\section{Utilization/Technology Base Advance}

Responsibility for most of the personnel-related issues was assumed by the Office of Personnel Management (OPM) in conjunction with OP.14. To date, OPM and OP.14 have either implemented or are in the process of developing action plans to correct impediment issues related to pay and position management, staffing, technical managerial training, and employment restrictions. The Naval Material Command has taken responsibility for all nonpersonnel-related items and is now developing action plans for issues in the general areas of material/equipment, supply support. and personnel issues that could be effected at the NAVMAT level. 


\section{Payoff/Potential}

The absolute payoff to be gained by removing the impediments to productivity cannot be determined until an appropriate period for monitoring and evaluating the various action plans has elapsed. Because no previous work of this type has been performed, there are no existing data from which estimates of expected benefits might be extrapolated. However, it is obvious that improvements not only in morale but in the procedures and support functions associated with the working environment in these activities will have a positive impact on productivity.

\section{IMPROVING THE MANAGEMENT OF RECRUITING RESOURCES}

\section{Need}

The cost of Navy recruiting is well over $\$ 100$ million a year. A major task of the Recruiting Command is the apportionment of the overall recruiting budget into resource categories and subcategories that will result in efficient recruiting at the lowest possible cost. For example, choices have to be made between buying more advertising and fielding more recruiters. Given a particular advertising budget, it is necessary to decide what types and amounts of media "buys" (national vs. local campaigns, TV vs. radio, etc.) are likely to result in the highest number of accessions. Decisions about recruiting budgets are complicated by external factors over which the Navy has no control but which can profoundly influence the numbers and quality of recruits. Two such factors are local unemployment rates and the numbers of high school seniors in an area.

Until recently the assignment of funds to budget categories had been based on educated debate and precedent. Resource allocation was imprecise. It was not possible to systematically co-vary the many factors that go into the overall recruiting equation so that dollars could be assigned in the best possible way. Ultimately, the measure of the success of budget or resource allocation comes down to one question: "Is the Navy recruiting enough people, and of the right ability mix, to man the force?"' If the Recruiting Command can apportion its budget categories so that accession goals are met, the answer to that question will be a positive one. But in the majority of recent years the Navy and other services have not met their objectives. It was clear that some means had to be found to improve the resource-allocation process.

Research leading to the development of improved techniques for budget allocation was initiated by the Recruiting Resources Allocation Study, under the direction of the Deputy Assistant Secretary of the Navy (Manpower); the Commander, Navy Recruiting Command; and the manager of ONR's Manpower R\&D program.

\section{Performing Activity and Program Element}

The Office of Naval Research was responsible for this effort, which was performed under contract.
Funding was provided under Program Element $62763 N$. Program dynamics in support of this effort are depicted in the following diagram.

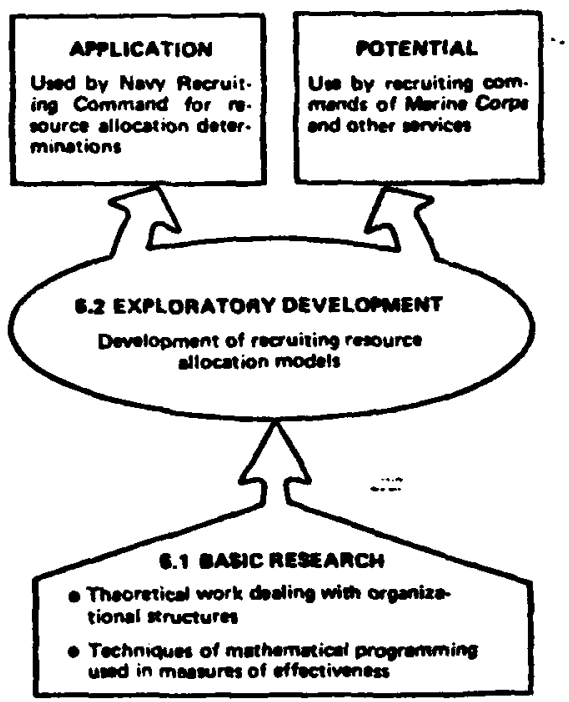

\section{Approach and Reaults}

Computer-based models were developed in close cooperation with members of the headquarters staff, Navy Recruiting Command. The models use as the dependent variable the number of high-school-graduate enlistment contracts. (High school graduates are the Navy's prime recruiting target, and because they are a scarce resource there is a great deal of competition for them from the other services.) Included as independent variables are, among others: number of recruiters, advertising dollars, unemployment rate, number of male high school seniors, civilian-to-military pay ratios, and seasonal effects-all of these aggregated at the level of the recruiting district. Before the models were used they went through an extensive validation phase. Models were also run on previous-year data: Savings of from 3 to 4 percent in recruiting costs were shown to have been possible, at no loss in quality or number of recruits, had resource allocation been optimized. 
The principal output of the models is a regression equation that predicts the supply of enlistments. The models can be used in either direction-to predict accessions for a given set of resources or to estimate necessary resources for a required level of accession. Specifically, these kinds of questions can be answered: "Given a recruiting goal for male high school graduates, what is the lowest cost-mix of advertising and recruiters required to attain that objective? Given a budget, how many accessions can be attained by varying the mix of recruiters and advertising? Given resources of recruiters and advertising, how many high school graduates can be recruited?"

Additional outputs of the models are recommendations for the timling of advertising and its geographic distribution. The models also make it possible for the Recruiting Command, with a Five Year Defense Plan (FYDP) resource profile, to predict the number of recruits that can be expected to join the Navy. The models can be adjusted to account for changes in recruiting policy (for example, a decision to reduce the proportion of high school graduatesl, changes in the economy, changes in the numbers of recruiters authorized by Congress, or demographic changes (reduced numbers of high school students, for example).

\section{Utilization/Technology Base Advance}

The resource allocation models were introduced into the Recruiting Command's budget preparation process, or POM (Program Objectives Memorandum), in 1980. They have since become part of the standard procedure, having been applied to POM 82 and POM 83. The Recruiting Command has said that the models have led to a "significant increase in management capability" in meeting recruiting gouls at the lowest possible cost. Follow-on work is under way to refine the number and type of variables used and to fine-tune the models' output. It should be possible, for instance, to examine different economic scenarios to see how each might affect the future supply of personnel.

\section{Payoff/Potential}

The overall recruiting climate for the Navy is likely to worsen in the foreseeable future: the number of 17.20 year-olds is dropping, propensities to serve in the Navy are lessening, and competition for youth-from industry and from colleges-is increasing. At the same time there are pressures to reduce budgets and show links between expenditures and output. It has always been difficult to demonstrate that dollars spent- for recruiting result in a particular outcome. The resource allocation models are an important step in the direction of accountability and cost saving.

In their application by the Recruiting Command to the FY 82 and FY 83 budget forecasts, the models provided budget inputs based for the first time on quantified external factors such as projected unemployment. Determination of such quantifiable relationships is a major step toward establishing and supporting effective recruiting resource levels. As an additional benefit, use of the models has thus far saved four man-months of analyst/statistical assistant labor each year.

The Marine Corps is considering the possibility of adapting the technique to its recruiting needs.

\section{COMPUTERIZED NAVY RECRUITING, ASSIGNMENT, COUNSELING, AND TESTING}

\begin{abstract}
Need
At present, recruit applicents are assigned to Navy jobs on a first-come, first-served basis. Assignments are made manually by classifier personnel located at each Armed Forces Entrance and Examination Station (AFEES). Because each AFEES produces a relatively small yearly pool of applicants, from which the local classifiers must fill a proportionate number of Navy billet openings, the assignment decision cannot adequately take into account individual factors. It frequently neglects matching personnel of a given ability level with jobs whose requirements are appropriate for that level, and often lacks response flexibility with respect to changing Navy priorities.
\end{abstract}

Representatives from the Naval Military Personnel Command (NMPC) and the Navy Recruiting Command (NRC) requested that the Navy Personnel Research and Development Center (NPRDC) develop a comprehen. sive classification procedure for non-prior service males that addresses these problems. It should automate the assignment function, employing an optimal-sequential algorithm similar to the one on which the Air Force assignment system is based.

Performing Activity and Program Element

This project was performed by the Navy Personnel Research and Development Center. Funding was 
provided under Program Element 63707N. Program dynamics in support of this effort are depicted in the following diagram.

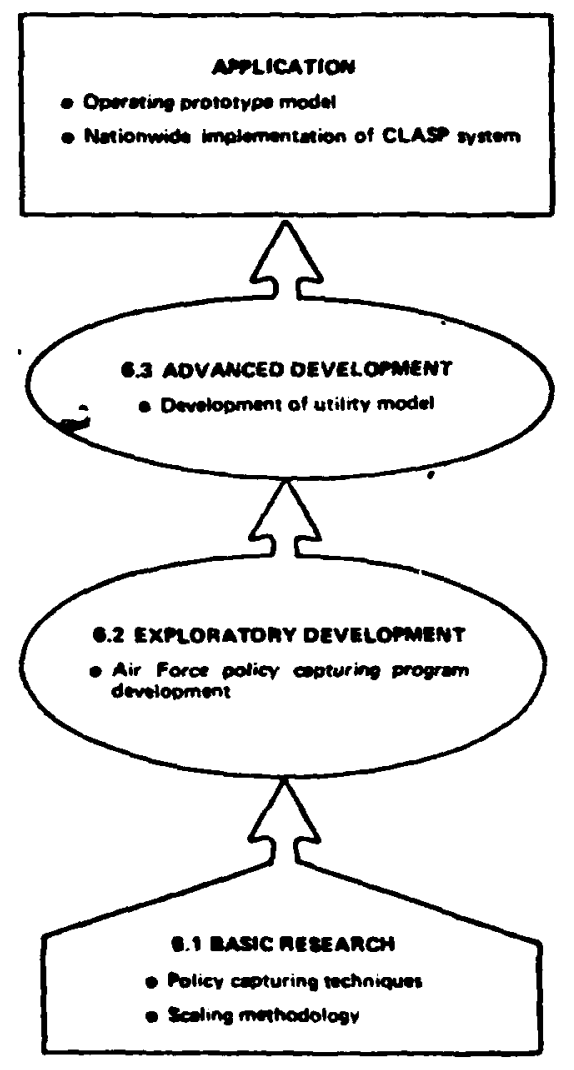

\section{Approach and Results}

A number of critical features were identified that should be designed into the model. These were:

- The model should be additive (that is, built and installed in a component-by-component fashion, for easier implementation).

- It should be suitable for use with an optimal. sequential algorithm (program 'ogic) that takes into account applicant arrival rate.

- It should be compatible with NRC goaling procedures.

- It should be compatible with the Navy's current automated school-seat reservation system (Personalized Recruiting for Immediate and Delayed Enlistment, or PRIDE).

- It should require no additional time for classifi. cation.

First, the Air Force assignment system was investi. gated and a number of design concepts were adapted for use in a system unique to the Navy. NPRDC researchers then derived functional forms of the various model components using a policy capturing program developed by personnel at the Air Force Human Resources Laboratory. The development effort resulted in a prototype assignment model known as CLASP (Classification and Assignment within PRIDE). NPRDC personnel then conducted field tests and operational impact investigation.

\section{Utilization/Technology Bas Advance}

This research effort has received input information and guidance from three primary sources, as shown in the following diagram. Information concerning model requirements, program objectives, short- and long-term recruiting goals, and potential effects on operational capability has been exchanged among the three agen. cies throughout the project.

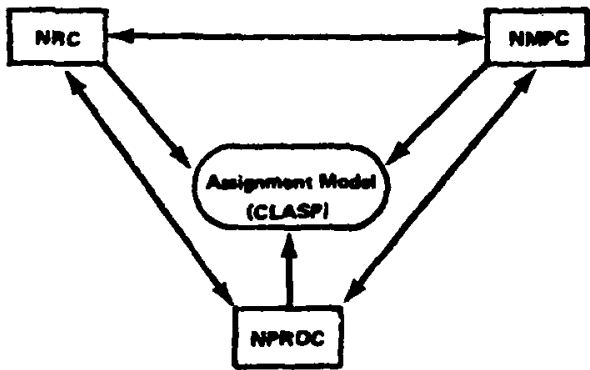

Participating Oramization

The operation of the CLASP prototype model has: been demonstrated to NRC and NMPC representatives. Computer programs prepared by NPRDC personnel have been forwarded to NRC, whose programmers are currently incorporating the computer code into the PAIDE reservation system.

NPRDC researchers have conducted numerous briefings for various decisionmakers at NRC and NMPC. The technical development of the methodology has been reported at several conventions, and will appear as NPRDC technical reports.

\section{Payoff/Potential}

During FY 80, a large proportion of the more than 100,000 Navy applicants who were processed through the AFEES were assigned to jobs that require initial A-school training. The assignment model developed in this project will improve the classification of a significant number of these recruits (the non-prior service males).

Because the automated assignment system has access to a much broader base than do the individual AFEES, it can more accurately take into account both the individual's capabilities and preferences and the current system requirements of the Navy. The net effect is that more appropriate assignment (and, thus, training) take place, producing better-trained personnel more likely to remain in the service through their first enlistment and beyond. 
The operational cost of the assignment system is approximately balanced by the cost involved in replacing one Navy attritee per week. Once CLASP is fully operational, it will account for many times this level of savings. The overall savings-to-investment ratio for the program, including development and start-up costs, has been estimated to be 2.6 to 1 .

NMPC is planning to extend assignment model operation beyond non-prior service males, to include reserve personnel, fleet personnel, female personnel, and other categories.

\section{BILLET COST MODELS}

\section{Need}

Hardware systems being introduced today are increasingly complex and technologically advanced. Fraining the skills required to man these systems is expensive, and adds to the system support costs. When a large proportion of highly skilled and experienced personnel are required to man and maintain such a system, the operational costs can become prohibitive.

A tool was needed that would permit these manpower and training support requirements and costs to be considered quantitatively along with other design trade-off variables during the design phase of each weapon system procurement. The selection of design characteristics that are economical in terms of manpower will reduce life cycle costs for a system and make it more practical to man and maintain. Such a tool could also be used by force structure planners and budget managers to develop more accurate forecasts of Navy-wide manpower costs, for planning and programming purposes.

\section{Performing Activity and Program Element}

This work was performed by the Navy Personnel Research and Development Center (NPRDC) under the sponsorship of the Deputy Chief of Naval Operations (Manpower). OP-01. Reimbursible money funded a portion, with the remainder being provided under Program Element 63707N. Program dynamics in support of this effort are depicted in the following diagram.

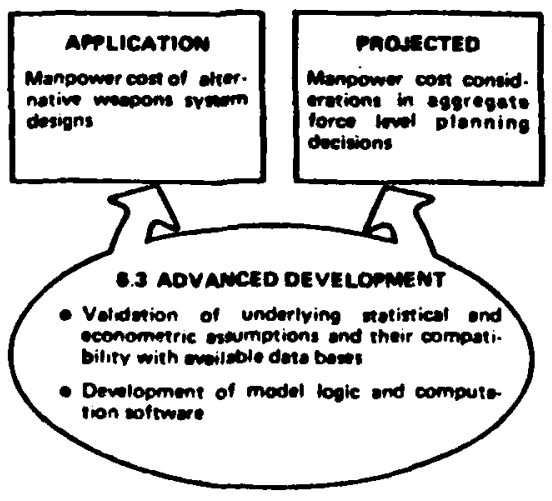

\section{Approach and Rosults}

NPRDC has developed an integrated system of four Billet Cost Models (BCMs) representing officers and enlisted personnel, reserves, and Navy civil service employees. Each BCM provides estimates of the annual and life cycle costs of manning authorized billets with people of specified skills (ratings) and levels of experience (pay grades) in each of the four categories.

In addition to computing life-cycle manpower costs for individual weapons systems, the cost models can estimate life cycle manpower costs Navy-wide. The models view manpower as a dynamic system in which personnel are seen as flowing up through ratings or grades, as well as through each billet. Personnel in the system are procured, trained, and utilized, and as time passes they are lost through attrition, non-reenlistment, death, or retirement. The costs include all expenditures charged to operational billet years (normally a "life cycle" of 30 years), expressed on a year-by-year basis.

\section{Utilization/Technology Base Advance}

The four BCMs that have been developed represent all major areas of Navy manpower expenditures. Currently, both military and civilian contractors have made use of the BCMs in costing manpower requirements. Some users have been:

- NAVSEA - to determine the manpower costs of operating and maintaining the Vulcan Phalanx Air Defense System.

- Naval Underwater Systems Center-to study cost trade-offs in automating selected SSN billets.

- Naval Audit Service (San Diego)-to assess enlisted versus civilian billet costs for tug and small craft operations.

The models are now undergoing transition into the management control of the DCNO. Manpower, where provision will be made for tailoring them for uses in programming and force structure planning, and for maintaining them. Through OP-01 the BCMs will also be made available for more widespread application to weapon system design procurement. 


\section{Payoff/Potential}

The development of accurate manpower cost data relative to future weapons systems can lead to substantially lower overall life cycle costs. Alternative design concepts entail different manning configurations, and thus have different costs and place different demands on the Navy's training system. If choices are made that take these factors into account in a systematic way on each new system to be fielded, the overall gain in efficiency and readiness Navy-wide will be substantial-as will be the cost savings.

In addition, the use of BCMs to provide forecasts of aggregate Navy costs will greatly simplify portions of the Planning, Programming, and Budgetary System (PPBS) cycle.

\section{TRACKING GENDER-INTEGRATED CREWS}

\section{Need}

Until recently, Navy women were precluded from serving on ships at sea. In 1978, at the urging of the DoD, the Federal Code was modified to permit their assignment to noncombatant ships. This change gave Navy managers more flexibility in the utilization of personnel resources, opening new career fields to women and preserving equitable sea/shore rotation schedules for men.

However, gender integration at sea represents a sharp break with tradition, and has required adjustments on the part of management and personnel of both sexes. Because the change is not an experiment, an attempt had to be made to capture the process as it has evolved on the first ships to be affected, and to look within that process for ways of aiding the transition on future ships.

\section{Performing Activity and Program Element}

This project is being performed at the Navy Personnel Research and Development Center in response to Navy Decision Coordination Paper NDCP-21326-PN, under the sponsorship of OP-01. Funding was provided by Program Element 63707N. Program dynamics in support of this effort are depicted in the following diagram.

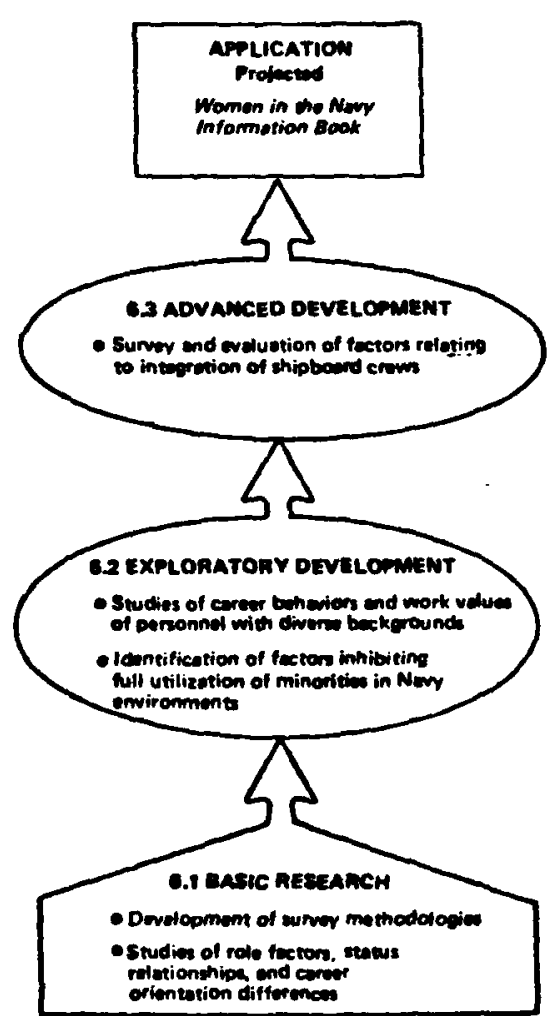




\section{Approsech and Recults}

The methodology being used applies the techniques of social psychology and anthropology to the analysis of personnel interactions in the shipboand environment. It includes surveys, site visits, interviews, and tours by participant/observers. The ten ships to which enlisted women were assigned during $F Y 79$ and FY 80 are the target population. The crews of each ship were given the preintegration form of the "Navy in Transition" survey before the women came aboand. The postintegration form of the survey is being given about 9.12 months later. Between these two dates, Navy reservists with a background in behavioral sciences function, as unobtrusive observers. Over a two-week period, their task is to record incidents illustrating level of morale and equality of treatment aboard shilp, and data regarding women's job effectiveness.

In the analyses, background and attitudinal variables are being linked to individual adjustment to mixed-gender crewing. Comparisons are being made of job satisfaction, reenlistment intention, and morale before and after integration. Data gathered during the observational periods are being used to provide examples of the actual behaviors that are associated with attitudes expressed in the postintegration survey. Comparisons are being made among ships, and the attempt is being made to develop explanations for differences that are found.

The results to date reveal the strong effect of organizational variables on the preintegration attitudes of the men in the crews. That is, there were substantial differences among those in the different depertments, at the various paygrades, and with different lengths of service in the Navy. Among the individual variables, age and education were highly related to attitudes toward women's role in the workplace and expectations about the treatment of women aboard ship. Women who were surveyed prior to coming aboard ship had attitudes and expectations in these regards that were generally different from those of men.

\section{Utilization/Tochnology Base Advance}

A series of "lessons learned" will be developed from the results of the research. These insights and examples will be incorporated into the Women in the NaW Information Book by the Naval Military Personnel Command. The intended users of this book are ships having or about to have mixed crews, and also shore commands that are integrating formerly alt-male units.

\section{Payoff/Potential}

The potential advantage to be gained from the integration of ships is great in terms of improved manning levels, shortened sea duty tours for men, and savings of recruiting funds (as the pool of recruitable manpower shrinks, each additional person recruited costs more than the last; the assignation of women to shipboard billets enlarges that pool). If, on the basis of this study, concrete ways of promoting successful gender integration on ships can be derived, the cost of the research will be more than recovered through such savings.

\section{PERFORMANCE-BASED INCENTIVE SYSTEM FOR GREATER PRODUCTIVITY}

\begin{abstract}
Need
Personnel costs are the largest single item in the defense budget. Consequently, the need to substantially reduce personnel costs and increase productivity without undermining the long-range quality and effectiveness of the workforce is a major Navy-wide concern. The traditional way to increase productivity has been through advances in hard technology; how. ever, in recent years the acquisition of new equipment has been particularly difficult for the Navy and other Government agencies. Increasing the productive
\end{abstract}

efficiency of the individual worker with innovative personnel systems is therefore viable alternative to hardware acquisition.

\section{Porforming Activity and Program Elemont}

The research for this project was conducted by NPRDC under the sponsorship of the Pearl Harbor Naval Shipyard. Although reimbursable money funded this work, the methodology was originally developed at NPRDC under Program Element 62763N. Program dynamics in support of this effort are depicted in the following diagram. 


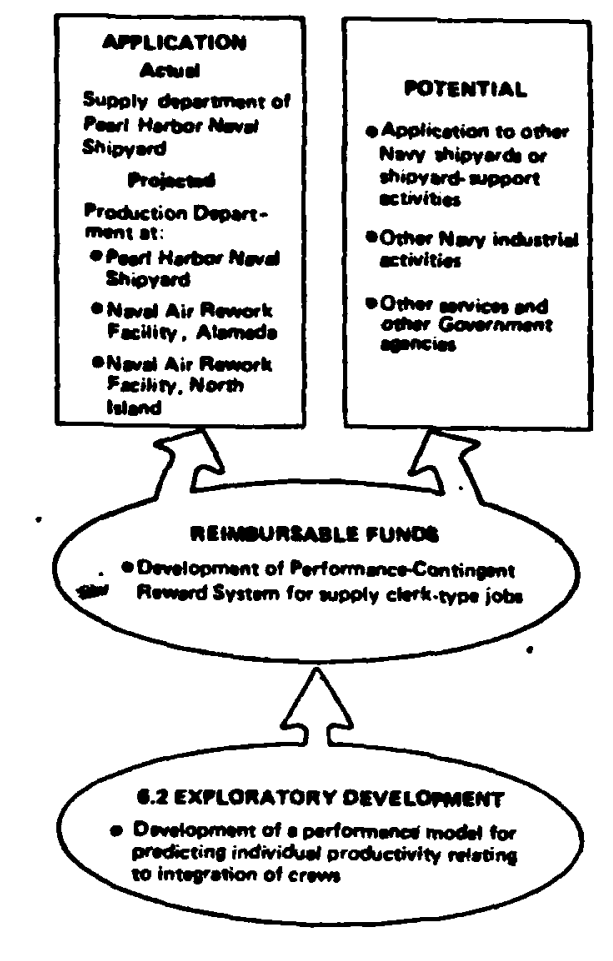

Approach and Results

The use of monetary incentives to increase personnel productivity has long been practiced successfully in civilian industries. An approach of this type, using the Performance-Contingent Heward System (PCRS), was applied to clerical-type jobs in the Supply Department of a Navy shipyard. The first step was to develop performance standards for these jobs (supply clerks and small-purchase buyers). Essentially, the standards define the amount and quality of work expected of an employee. When an employee chooses to perform at a level beyond that which is expected, the additional productivity "saves" production costs. In practice, the cost savings results from the organization's ability to either produce at a higher level with the same number of employees or produce at the same level with fewer employees. Under the Performance-Contingent Reward System (PCRS) developed in this effort, between $\mathbf{3 0}$ and $\mathbf{5 0}$ percent of these labor cost savings are returned to the employees producing the sevings; no more than 20 percent of the savings is required to run the PCRS program itself, and the remainder is passed on to consumers in the form of lower per-unit costs.
The PCRS was initiated in the Supply Department at the Pearl Harbor Naval Shipyard in November 1979. An evaluation of the program was run between June 1980 and September 1980. Comparative analysis of the 17-week evaluation period with a baseline period (the same 17-weok period in the previous yearl showed a 26 percent reduction in overall labor costs, yielding a $\$ 110,000 /$ year net savings at this activity (costs of initial program setup not included).

\section{Utilization/Technology Ban Advance}

Based on the results of this PCRS implementation, NPRDC has begun to develop PCRSs for the Production Departments of the Pearl Harbor Naval Shipyand and of the Naval Air Rework Facilities at Alameda and North Island. A mechanism that will allow the smooth transfer of these personnel technologies to other activities is in the early development stage.

\section{Payoff/Potential}

A cost benefit analysis has been performed on the data generated from this program. Using this formula:

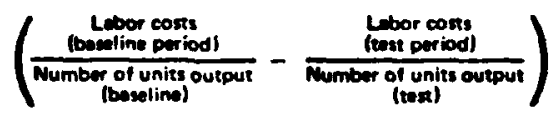

$x$ (Number of unite oureut (ara))

- Lebor cos sevings (test period):

the ovarall savings during the 17-week test period was:

$$
\left(\frac{\$ 178,436.97}{21,763}-\frac{\$ 166,491.91}{24,704}\right) \times(24,704)-\$ 35,058.60
$$

With the initial costs of program development and implementation prorated over a 2-year period, this program will vield a net labor cost savings of over $\$ 500,000$ within a 5-year period (1980 dollars). Net yearly benefits will increase after the prorated period. There are six other Navy shipyards, or supply activities that support shipyards, which could employ the methods developed at Pearl Harbor Naval Shipyard. Extrapolating the savings produced in this one test implementation over those activities and other production-oriented activities to which the PCRS is applicable, the potential for labor cost sovings lor greater productive output) becomes quite large. 


\section{HUMAN FACTORS ENGINEERING}

DoD defines this area of People-Related RDT\&E as follows:

"Development of improved methods and technologies for the analysis, design, and evaluation of equipment/systems for safer and more efficient operation and maintenance."

The Navy needs equipment and support systems designed in such a way that people can do their jobs faster, more accurately, and more safely when they operate, maintain, or control hardware. The Navy's research and development program in Human Factors Engineering is involved in all systems, from their initial formulation to test engineering specialists in various development agencies and contractor firms.

Projects in this category include:

- Planning for the Implementation of NTIPS

- Improving Air-to-Air Target Sighting

- Designing Computerized Decision Aids for Airborne Systems 


\section{PLANNING FOR THE IMPLEMENTATION OF NTIPS}

\section{Need}

The development and distribution of Technical Information (TI) in the Navy is currently a process that lends itself to greater inefficiency as the scale of application increases. The introduction of more sophisticated hardware and weapons systems means that Technical Manuals become more complex while the reading abilities of Navy personnel are, if anything. dropping. Delays are experienced in the provision of initial documentation for training, and in the updating of technical.materials to accord with altered hardware configurations. Duplication of technical materials is also a problem sparticularly between the training and logistics communities. And higher $\mathrm{TI}$ development and distribution costs are feature of each year's budget.

\section{Performing Activity and Program Elements}

The David W. Taylor Naval Ship Research and Development Center is technicaliy responsible for the development of NTIPS. Supporting research is being provided by the Training Analysis and Evaluation Group, Orlando, Florida. A support contractor is responsible for designing the system. Planning, programming, and budgeting for the implementation and continuing utilization of NTIPS, once it is designed, are being carried out by the Deputy Chief of Naval Operations (Logistics), the Deputy Chief of Naval Material (Logistics), and the NTIP Program Office. Funding comes from Program Elements 62763N and 63727N. Program dynamics in support of this effort are depicted in the following diagram.

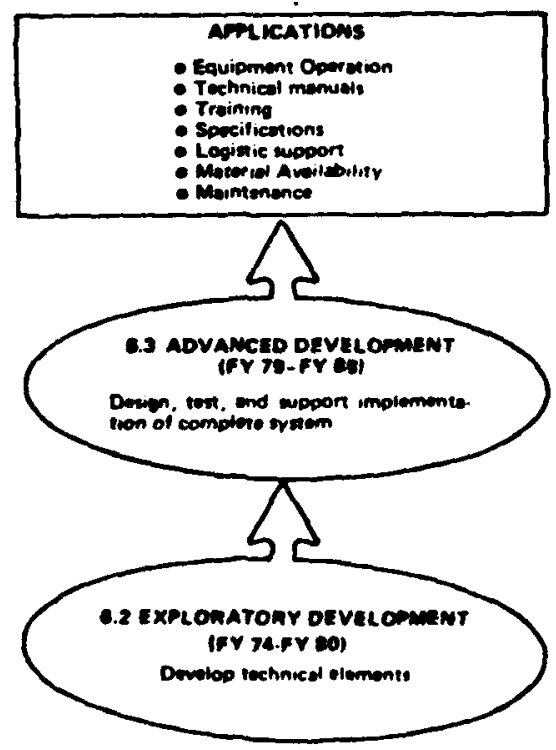

\section{Approach and Results}

Previous annual utilization reports have described progress in the design and development of a Navy Technical Information Presentation System (NTIPS), which is intended to solve many of the prevailing TI problems. NTIPS will be a cost-effective, integrated, Navy-wide system for the generation, distribution, and control of hardware-related Technical Information used in operations, maintenance, training, and logistics support. Relying on automated database techniques, it will translate engineering data on a new system directly into specifications for the necessary TI. This information will then be generated, replicated, and distributed in appropriate format through the use of state-of-theart text processing technology.

The NTIP development program is being carried out in three phases:

\section{System and Feasibility Tradeoff Analysis \\ II. Critical Element Testing and Detailed NTIP System Design}

III. Prototype Test and Implementation Recommendations.

Phase I has been completed. For a discussion of accomplishments and significant findings under this phase of the program, see the First and Second Annual Reports on the Utilization of People-Related Navy RDT\&E.

Phase II was initiated during FY 79. Previous accomplishments under this phase were detailed in the Third Annual Report on the Utilization of People-Related Navy ROT\&E, and included the completion of working design drawings for all NTIPS subsystems (TI Definition and Acquisition, TI Generation, TI Mastering and Replication, TI Distribution, TI Delivery, and TI Control). Critical elements of NTIPS were identified, and during FY 80 significant progress was made toward the detailed design of these elements. The figure lists the NTIPS critical elements that occur within each subsystem. Completion of the detailed NTIPS design is scheduled for the end of FY 81 .

During FY 80, plans were laid for two additional phases in the NTIPS effort, encompassing the actual implementation stage. Once the NTIP System design is completed (Phase II) and tested (Phase IIII, further 
Numerous technology-base advances have been realized during the development of NTIPS. Some of these advances include methods for matching the $T I$ to the user, to his tasks, and to the job environment; methods for ensuring that the TI meets the needs of the Training Community; methods for developing more comprehensible and usable TI: approaches to overcoming fleet users' resistance to change; methods for presenting $\mathrm{TI}$ using electronic display devices; and methods for users' reporting of TI deficiencies.

\section{Payoff/Potential}

NTIPS products such as these will assist the fleet in several ways. From the perspective of operators and maintenance technicians, they will bring about improvements in:

- Quality, accuracy, and consistency of Technical Information

- Homogeneity of technical content from school to job

- Efficiency of preparation and control of TI.

Greater use of automation in acquiring, controlling, and correcting TI will free badly needed man-hours in the fleet for operationally related tasks. Also, time saved aboard ship through the availability and use of more accurate and more efficient $\mathrm{TI}$ can contribute significantly to enhanced system availability and fleet readiness.

\section{IMPROVING AIR-TO-AIR TARGET SIGHTING}

\section{Need}

A critical element of tactical advantage in air combat is the early visual acquisition and continued tracking of airborne targets. Vietnam-era air-to-air acquisition data have shown that a surprisingly high percentage of initial target acquisitions were made visually (rather than by radar). This finding brought about a closer focus on problems associated with visual target acquisition. It has been found, for example, that actual air-to-air visual target acquisition occurs at ranges far inferior to calculated visibility ranges. When a target is acquired, it may be lost during brief glances away (for example, during instrument scan), and reacquired only with great difficulty or not at all. Also, aviators vary greatly in their ability to acquire airborne targets, even though each flier meets current visual standards. A related area of concern is that significant aircraft damage and personal injuries result from midair collisions which occur under visual flight rule (VFR) conditions. In light of these problems, OP.98 requested that an effort be undertaken to find ways to improve air-to-air visual target acquisition capabilities in the operational aviation community.

\section{Performing Activity and Program Elements}

This effort is performed as part of the Joint BUMED/NAVAIR Human Factors Vision R\&D pro. gram at the Naval Aerospace Medical Research Laboratory. Funding is provided under Program Elements
$62757 \mathrm{~N}$ and $63701 \mathrm{~N}$. Program dynamics in support of this effort are depicted in the following diagram.

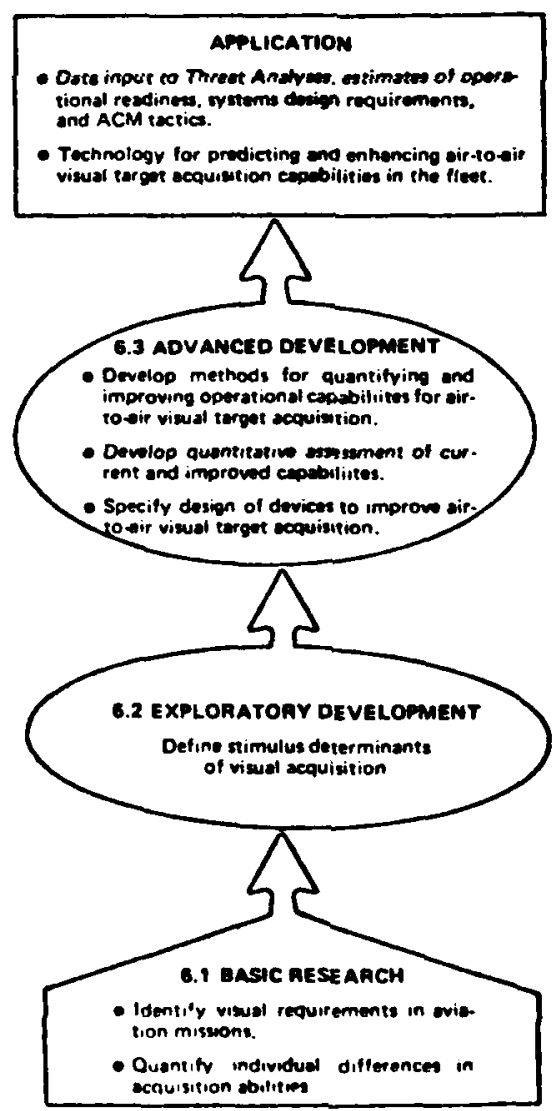




\section{Approach and Reuults}

The approach taken in this effort is to develop a battery of vision tests that can be used to select those aviation candidates who are likely to perform best in visual target acquisition, and to provide specifications for training devices that will help to enhance the visual skills of aviators.

The effort began with an assessment of the current levels of target-acquisition ability of aviators. This assessment, which was conducted on the Air Combat Maneuvering Range (ACMR), included a particular look at physical variables, such as peripheral vision and dynamic visual acuity, that affect performance in the air-to-air visual environment. Next, the inflight visual environment itself was analyzed with regard to the target acquisition function. Current knowledge about the visual functions that act to limit a flier's target acquisition ability was researched, and existing methods for testing or improving these functions were evaluated.

A simulated air-to-air acquisition environment was used to conduct initial validation of these existing methods, which included visual-function tests, training techniques, and various human engineering aids. On the basis of these simulation studies, items from each category were selected for inflight validation against air-to-air visual target acquisition criteria.

These efforts have led to the development of a Vision Test Battery, comprised of roughly 60 separate tests of such visual functions as peripheral vision and dynamic visual and oculomotor functions. The battery is designed so as to control the tests precisely under a large range of brightness and contrast conditions, at both near and far distances. Inflight experiments will narrow the field of tests to those which, taken collectively, are most accurately predictive of air-to-air visual acquisition performance. The inflight validation tests will also provide quantitative data on which to base estimates of both the current visual acquisition capabilities of Navy fliers, and the amount of improvement in these capabilities that can be expected through the use of the various selection, training, or human engineering methods tested.

In addition, the inflight tests will validate a Vision Detection Simulator which has been modified and calibrated for conducting the simulated air-to-air visual acquisition studies.

Initial measures of inflight performance have indicated a large variability among aviators in airto-air acquisition abilities, and lower acquisition ranges than would have been predicted from most laboratory data. These measures have indicated also that much of the variability in acquisition range is related to physical variables of the engagements, rather than to individual differences among the aviators. Examples of visual target acquisition data obtained during ACM training on the ACMR/ TACTS are presented in Table 1.

\begin{tabular}{|c|c|c|c|c|c|}
\hline & & \multicolumn{2}{|c|}{$\begin{array}{c}\text { Rate } \\
(N-\mathbf{6 3})\end{array}$} & \multicolumn{2}{|c|}{$\begin{array}{c}\text { Ronge } \\
(N-35)\end{array}$} \\
\hline & & $\begin{array}{c}\text { Units } \\
\text { Engaped }\end{array}$ & $\begin{array}{l}\text { Acquisi- } \\
\text { rion } \\
\text { Aote (\%) }\end{array}$ & $\begin{array}{l}\text { Acquisi- } \\
\text { tions }\end{array}$ & $\begin{array}{l}\text { Acquisi- } \\
\text { tion } \\
\text { fange (ft) }\end{array}$ \\
\hline Fighter & F.14 & 23 & 78 & 18 & 16481 \\
\hline Squedion & $F-4$ & 30 & 60 & 17 & 13700 \\
\hline Advereory & $A-4$ & 35 & 74 & 26 & 15904 \\
\hline Squadron & $F 5$ & 18 & 56 & 9 & 12737 \\
\hline Time of & $0900-1100$ & 19 & 63 & 11 & 17353 \\
\hline \multirow[t]{2}{*}{ Dor } & $1100-1300$ & 16 & 88 & 14 & 11958 \\
\hline & $1300-1500$ & 18 & 56 & 10 & 17140 \\
\hline Bogery & High & 37 & 77 & 28 & 15155 \\
\hline Position & Low & 16 & 46 & 7 & 15052 \\
\hline
\end{tabular}

\section{Utilization/Technology Base Advance}

The Vision Test Battery being developed here is not yet in final form; however, results and interim developments emerging from the effort have already contributed to much-needed progress in the field of vision assessment and training. The technology base has been advanced through development of (1) specific methods of presenting stimuli for each vision test, (2) quality control of the stimuli, and (3) the determination of ranges of independent variables (target size, exposure times, velocities), testing times, and procedures for each test. The technology and prototype development required for obtaining precision test stimuli have been made available to other DoD labora. tories.

Associated exploratory development efforts have investigated features of visual stimuli that serve to enhance or degrade visual target acquisition, and have explored the validity of assumptions in the design of virtual image displays (head-up display, or HUDI regarding the time required to glance from an external target to the display to obtain information.

Products of this effort will include (1) specifications for vision tests and training devices that have been shown to be beneficial in predicting or enhancing acquisition performance, (2) a user's guide describing visual tests and training methods, and (3) an extensive data base for assessing visual detection performance in 
the training and operational environments. These products will have the following uses:

- Data representing fleet capabilities for air-to-air visual acquisition can be used in threat analyses and estimations of operational readiness, and by systems developers for determining system requirements.

- Characteristics of the visual acquisition process, and flight variables influencing the probability of acquisition, can be used by operational and training personnel for improving air-to-air tactics.

- Individual differences on the Vision Test - Battery can be used in determining visual screening standards, and in determining pipeline assignments during aviation training.

- The availability of special visual training for inflight target acquisition will be a new factor in determining training requirements for aviation personnel.
The Visual Flight Battery can be used by naval air training activities such as the Fighter Weapons School, and by AIRLANT and AIRPAC, to screen pilots for special missions and assignments (such as to the new F-18). Contingent upon the successful validation of the battery, the Bureau of Medicine and Surgery will eventually use it to screen candidates for flight training.

\section{Payoff/Potential}

In addition to improved estimates of fleet capabilities, benefits to ACM tactics and systems design, and reduction in losses due to midair collisions, it is estimated that the improved visual screening and specialized training resulting from this effort will improve air-to-air visual acquisition effectiveness of fliers by at least 50 percent.

\section{DESIGNING COMPUTERIZED DECISION AIDS FOR AIRBORNE SYSTEMS}

\begin{abstract}
Need
Technological advances in airborne systems have brought about an information overload of such magnitude that operators are increasingly unable to perform required actions within the limited time available to them. Now, the same processor and control/display technologies which produced this overload are being used to support the operator's information processing functions. Attempts to automate specific tasks le.g., processing and screening raw sensor data, continuous recordkeeping, and recall of technical and tactical information) have been successful, with the automation proving to be not only effective, but often more reliable than the operator. Recent advances in decision analysis, artificial intelligence, and pattern recognition have brought about widespread agreement that the use of "intelligent systems" to augment and/or automate human functions is not only feasible but necessary in order to compensate for man's inherent disadvantages in keeping pace with the capability offered by technology.
\end{abstract}

What is less widely understood is that inappropriate engineering of such systems can materially worsen an already severe operator workload situation. Current efforts toward cockpit automation exhibit a distinctly piecemeal approach. Functions associated with a single subsystem or a single sensor are being addressed without considering the total job of the operator or the implications of automation that may be taking place in other subsystems. Too often this approach removes from operators those tasks they perform well unaided, leaving in their control only a collection of complex activities that were not understood well enough to automate. This approach is not adequate. Development of intelligent systems requires especially rational design engineering if it is to avoid the trap of inappropriate automation lautomation that contributes to, rather than solves, problems at which it is directed). The Decision Augmentation Systems (DAS) program addresses this burgeoning need for special techniques to design systems that make heavy use of task automation. 


\section{Performing Activity and Program Element}

This work is performed by the Naval Air Development Center (NADC) under Program Element 62757N, with the assistance of the Naval Weapons Center. Program dynamics in support of this effort are depicted in the following diagram.

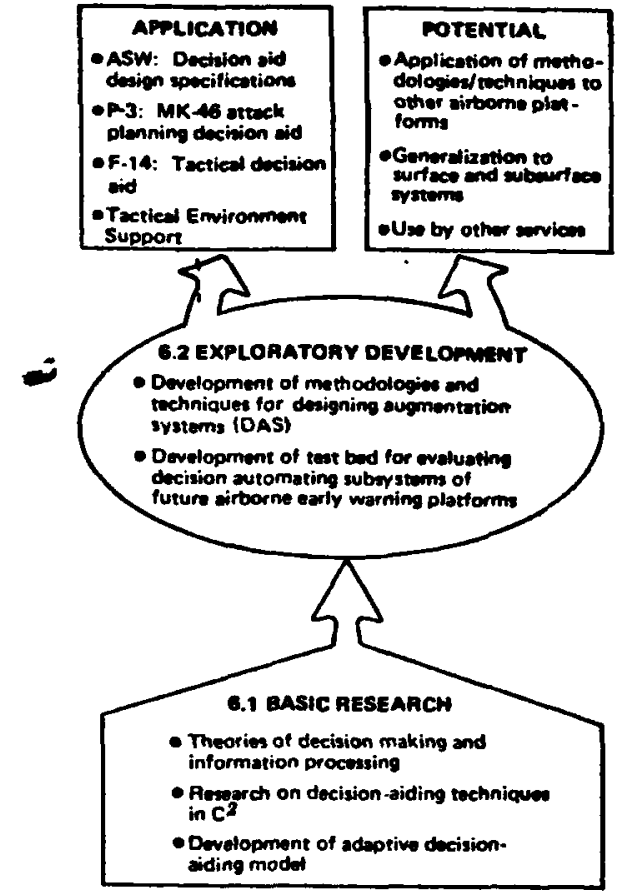

\section{Approach and Results}

Determining where and how task automation and operator augmentation will be used requires a system. atic approach. The DAS program addresses the problem of intelligent-system design by defining, developing, and applying appropriate design techniques for use with operationally diverse airborne platforms. The approach is to focus on the operator's specific needs for assistance in a variety of mission contexts, and then to generate candidate ways of addressing these needs. An important aspect of the work has been the search for objective criteria and methods that can be used to select the most promising automation and augmentation candidates and to evaluate them throughout their development to see which gives the best performance. Each step in the engineering design process requires analysis and evaluation techniques that are specifically tailored to the design augmentation and automation systems. Analysis mechanisms being developed range from formal front-end analysis and problem definition, through part-task simulation and computer models, to evaluation methods employing high-fidelity hardware simulators and operational software. In addition. consideration is given to such issues as user acceptance of intelligent systems and planning for degraded-mode operations that are unique to systems such as these.
The general goal of this program is to improve mission performance by enhancing the effectiveness of information management within the total avionics system. There are many aspects of this overall decision-making environment that must be understood and integrated before that objective can be achieved. Thus far, efforts have centered on: (1) identifying key decision situations and matching them to available decision-aiding techniques; (2) eliciting the opinions of experienced operators about problems in unaided information processing tasks, and consolidating these opinions into a useful framework; (3) estimating the effectiveness of candidate augmentation and automation algorithms through the use of models; (4) determining the extent and types of augmentation/ automation algorithms that are supportable by current and future generations of airborne information processors; and (5) deriving information requirements and design parameters for proposed decision-automating components of airborne command/control systems of 1990-2000.

\section{Utilization/Technology Bace Advence}

This new technology has been transitioned to other Navy programs by sharing analytic results and by employing the new methodologies to address specific issues within those programs. In addition to the benefits these Navy programs derive, their use of the products helps to shape future directions of the DAS program by identifying shortcomings in ev st ng capabilities and pointing out types of design tei hniques needed. Products developed under the DAS program have thus far been applied in the following development efforts:

- Air Acoustic Performance Prediction-Specified design for 14 antisubmarine warfare (ASW) decision aids; determined feasibility of imple. menting these aids on airborne platforms with current hardware configuration and employing limited system modification (e.g., disk overlay).

- P-3 Update II-Development of a MK-46 attack planning decision aid for the P.3 aircraft.

- F.14 TDA Program-Development and evaluation of an F-14 tactical decision aid for multiple-threat intercept operations.

- Tactical Environment Support System-Evaluation of environmental inputs (such as mete. orological data) to planning tasks in air-to-air warfare (AAW), ASW, antiaircraft, strike warfare, and communications missions, so as to establish operational requirements.

Major parts of the work under DAS involve the process of transitioning prior ONR work in decision aiding (see 2nd and 3rd Annual Reports) into the 
DAS program. Additional work is funded jointly with the Command/Control Information Assessment ( $\left.C^{2} \mid A\right)$ Program. Current ONR/NADC Human Factors Engineering programs emphasize the development of ways to derive objective data about user needs for information-data that can support the design of decision aids. The aim of the joint $C^{2}$ IA/HFE program is to produce system analytic methods that can quantify information requirements and design parameters for decisionautomating features of airborne command/control systems of 1990.2000 .

\section{Payoff/Potential}

Computer-augmented systems for decision making are beginning to find frequent application in current and planned avionics systems that require high-speed, high-quality tactical decisions. Such "partial automa. tion is currently the only available solution to the increases in decision speed and information complexity that are characteristic of high-technology aviation systems. Decision-augmentation hardware and software can achieve major reductions in the processing load imposed on an operator; or they can create even more problems. The determining factor is the availability of design methods tailored to the special design and evaluation difficulties associated with auch systems. For designers who must solve both immediate and long-term application problems, the DAS program provides a sequence of validated techniques that guide systems development decisions from the earliest stages of a problem through the operational evaluation phase.

Other benefits may accrue in the area of cost savings, and savings in the allocation of Navy resources. If the operator's task load can be effectively reduced in an airborne system, then it may be possible to achieve a reduction in crew size. Additionally there is a potential to reduce the amount of training that is required for operators of these sophisticated systems. 



\section{SHIPBOARD TRAINING FOR THE SHIPBOARD ENVIRONMENT}

\section{Need}

The current system for Navy training requires that many personnel learn a major portion of their job tasks through shipboard training. For example, up to 50 percent of the engineering personnel reporting aboard surface ships have not received any technical school training; yet they must operate and maintain complex systems such as the 1200 psi propulsion plant, which contains literally thousands of components. Even personnel who do attend shore-based school seldom have the opportunity to practice with the kinds of equipment and procedures they must work with on the job. Consequently, when they arrive at their first duty station they must supplement their shore school. ing with on-the-job training using specific shipboard hardware and procedures.

A method is needed for designing shipboard training that is compatible with the constraints of the operational shipboard environment, and that can meet the ship's needs for competent personnel to operate and maintain the complex systems. Much of the research in training technology and development has been directed toward the Navy's formal schools, rather than its working environments, and therefore most of the resulting instructional techniques are not suited for use aboard ship. To be successful, shipboard training must be tailored to meet the needs and the constraints of operating Navy ships.

\section{Performing Activity and Program Element}

This project was performed by the Navy Personnel Research and Development Center. Research and development funding was provided under Program Element 63720 N. Program dynamics in support of this effort are depicted in the following diagram.

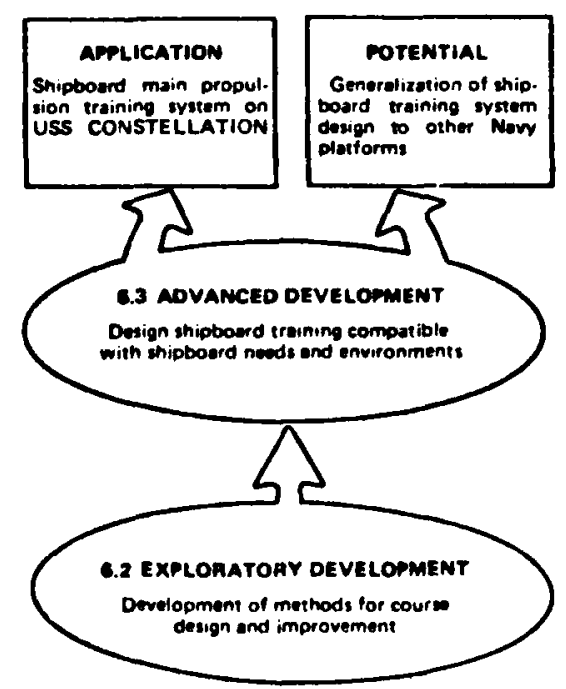

\section{Approsch and Results}

The development of a solution to shipboard training problems required the following sequence of steps: (1) definition of performance problems based on ships' needs, (2) determination of solution requirements and alternatives based on fleet priorities and environmental considerations, (3) selection of a solution strategy, (4) implementation of the solution strategy, and (5) evaluation of the effectiveness and generalizability of the solution strategy.

A survey of several hundred personnel aboard aircraft carriers identified main propulsion performance as the most critical problem in the fleet. Further analysis disclosed that the specific operational requirement was to establish a qualified three-section steaming watch. That is, a training program was needed that would qualify propulsion personnel to perform all major plant operational tasks. This program must be performance oriented and designed for use "on the deckplates," with instructional materials that are sufficiently self-explanatory so that personnel can learn on the job with some peer tutoring but without formal instruction.

A complete Shipboard Propulsion Plant Operator Training (SPPOT) program was developed which consists of procedural training aids, equipment and piping location aids, and instructional modules. The procedural aids (SPPOT Guides and Supplements)

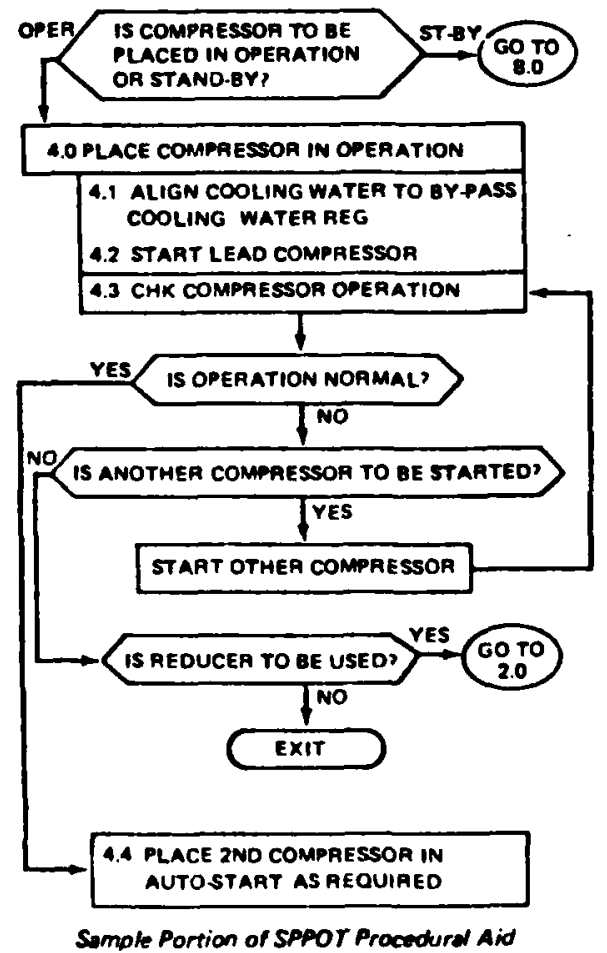


assist the operator in learning how to operate the propulsion plant by presenting step-by-step procedures, including action alternatives (see figure). The locational aids enable the operator to identify the equipments and trace the piping systems he is working with. The instructional modules provide basic training information common to all watchstations, and detailed information required for operation of the equipment and systems for each of the 13 epecific watchstations. SPPOT also contains the materials necessary to integrate this training program with existing shipboard systems such as the Performance Qualifications Standands (POS) system.

\section{- Utiliziotion/Tochnologr Baes advenee}

The-SPPOT products have been developed and implemented aboard USS CONSTELLATION (CV 64). The initial results of this pilot ship application have been so promising that additional applicitions to other platforms are now in progress, SPPOT materials are being tailored for use aboard USS SARATOGA (CV 60) and USS ROARK (FF 1053). The Conventional Marine Propulsion Training Steering Committee is currently developing plans for generalizing SPPOT to all 197 600-1200 psi propulsion plant ships.

This program represents one of the largest shipboard training programs ever attempted. It has demonstrated that it is possible to develop a practical training system which satisfies the actual shipboard performance requirements and which functions within the constraints of the real-world environment of operational ships. The SPPOT program was not focused on a small problem area, but addressed instead a major performance problem involving, in the case of USS CONSTELLATION, approximately 180 ; rsonnel. The success of the program can be attributed ..1 part to the fact that it was developed throughout in accordance with needs perceived by the users, and was tailored to meet critical performance requirements without placing additional training burdens upon the ship.

\section{Payoff/Potential}

The SPPOT program will improve fleet readiness in the following ways:

- Ships will be able to qualify and maintain a three-section main propulsion watch, which will enhence the capability of ships to steam on a 24-hour basis.

- Relatively inexperienced propulsion engineering personnel will be able to function as compotent operators.

- Objective performance evaluations will provide the fleet with an sccurate aseasement of its propulsion performance capabilities.

- The training program will compensate for the attrition of senior personnel who are needed to serve as experienced operators and as instructors for new personnel.

- Procedural training aids will provide a meens to conduct hands-on operational training despite - fleet-wide reduction in opportunities for practice under steaming conditions.

- SPPOT provides a prototype model for design of onboard training compatible with operational shipboard environments.

In eddition to the current benofits, efforts under way to generalize SPPOT to 197 combatant vessels will result in fleet-wide poyoffs in costs and operating copabilities.

\section{INSTRUCTIONAL QUALITY INVENTORY: QUALITY CONTROL FOR COURSEWARE}

\section{Need}

Many military activities currently use instructional Systems Development (ISD) procedures to develop or revise their training courses. However, the original ISD method did not provide for quality assurance: There was no way to determine whether instructional materials developed according to ISD actually taught the specific skills and knowledge needed for Navy jobs, and whether they taught them effectively enough. Later performance on the job was not assessed quantitatively in a way that could provide foedback for correcting inadequacies in training materials, with the result that subsequent improvement of courseware was unlikely. And in the case of materials developed by contractors. some means was needed to assess the quality of the product before it was accepted by the procuring activity.

Because the ISD method lacked internal provisions for quality control and evaluation, the procedures followed in developing military instruction did not necessarily produce successful training packages. 
Instructional development was more an art than a science, and subject to the same variability and subjectivity.

\section{Performing Activity and Program Eloments}

This project was performed by the Navy Personnel Research and Development Center (NPRDC). Funding was initially provided under Program Element 62757N. and later under 63720N. Program dynamics in support of this effort are depicted in the following diagram.
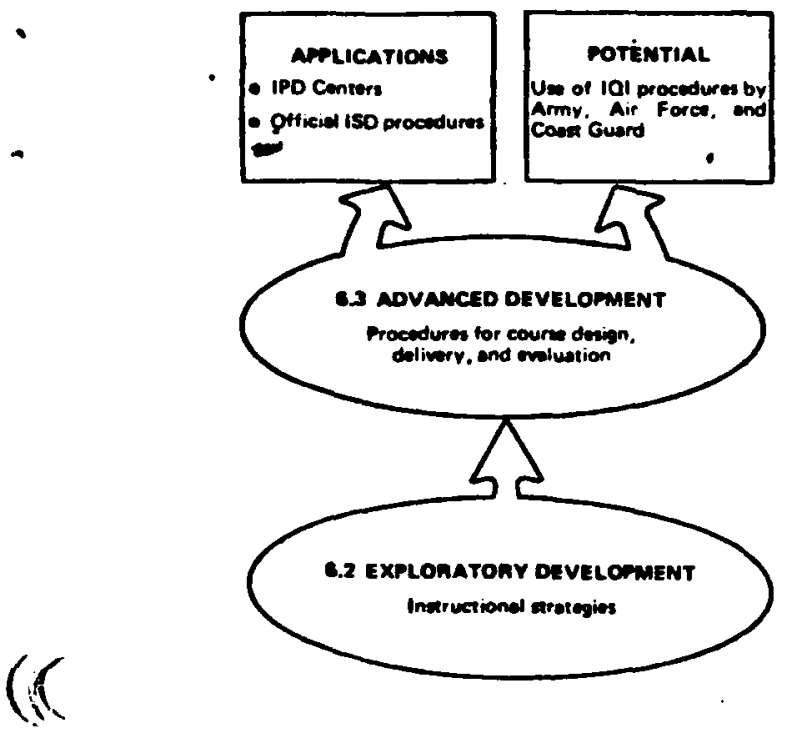

Approach and Results

In 1977, NPRDC initiated an effort to develop a scientific methodology for diagnosing defects in instructional materials. The resulting procedures, known as the Instructional Quality Inventory (IQI). were designed to parallel the ISD process and satisfy the need for quality control. They are based on a system for classifying the instructional objectives, test items, and presentation format according to the particular training application and type of learning involved.

The Ial procedures are used to (1) assess the adequacy of learning objectives, (2) ensure that objectives, test items, and instructional presentations are consistent with each other, and (3) analyze test items and instructional materials to determine if principles of learning have been correctly applied. This means that quality can be maintained throughout instructional development, so that errors made early in the development process are not amplified as development proceeds. In addition, existing materials can be evaluated with respect to newly derived training objectives to see if they need to be modified or revised; this is especially valuable where on-the-job performance difficulties have emerged among personnel trained with those materials. Lastly, contract monitors now have the means to objectively evaluate instructional programs and materials developed under contract.

\section{Utilization/Technology Base Advanes}

Since the 101 was first put to use in FY 78, its utilization has expanded significantly. The $\mid \mathrm{QI}$ is currently in use in all course development conducted at the Navy's Instructional Program Development Centers (CNETINST 1550.15, 29 May 1980), and has been mandated for use in all NAVEDTRACOM curriculum development (CNET Inst. 1550.15, 29 May 1980). The use of the $\mid \mathrm{QI}$ increases the reliability of the ISD process.

Over 30 workshops on the IQI have been conducted at operational training development activities across the country, including CNET, CNTT, NTEC, and the Great Lakes, Orlando, and San Diego Naval Training Centers. Workshops have also been conducted for the U.S. Coast Guard Institute, Oklahoma City-in which Air Force personnel participated-and for the U.S. Army Training and Doctrine Command. In addition, the American Educational Research Association has sponsored IQI workshops for the education community outside the military.

The Chief of Naval Education and Training (CNET) has adopted the IQI as an official part of Navy ISD procedures, and is incorporating it in forthcoming revisions of Navy ISD procedures publications. The 101 is in day-to-day use at the Instructional Program Development Centers at San Diego and Great Lakes, where it is being applied in developing schoo! curricula for Sonar Technicians, Data Systems Technicians, and several others.

\section{Payoff/Potential}

The IQI will be of substantial use to Training Program Coordinators in evaluating programs for the NAVTECHTRACOM, to instructors, course developers, and education specialists at Navy schools, and to Contract Technical Monitors who are responsible for training programs prepared under contract.

Formal comparative tests have shown the $|Q|$ to be effective in controlling the quality of training materials, and the comments of users strongly support that finding. Experimental tests of the IQI have shown that instruction revised according to $|Q|$ procedures leads to 10 to 20 percent improvements in student learning, achieved in substantially less time than 
students take to learn the original versions. In addition. the lal is able to shorten the time required for the design and development phases of ISO by from 10 to 25 percent.

Currently, the $|\mathrm{Q}|$ is being computarized so that the benefits of large-scale data menipulation and high speed can be applied to the tack of evaluating very large amounts of course material for the more than 4,000 Navy training courses.
The Ial will improve the general quality of technical training in the Navy, with benefits in manpower management and operational readiness. It will reduce the time and cost of developing and validating training programs; it will improve the quality of training materials produced in the Navy and under contract: and it will lead to increased student akill and knowledge while reducing training time.

\section{ECCM TRAINING THROUGH MICROPROCESSORS}

\section{Need}

Thiere is a critical need to improve fleet Elec. tronic Counter-Countermeasures (ECCM) readiness through training. ECCM involves recognizing, reporting, and reacting to hostile Electronic Countermeasures (ECM) such as jamming, chaff, and deception. Yet because ECM is considered to be an overt act of aggression, search and weapons radar operators have limited opportunity in peacetime to gain the experience and operational expertise needed to perform adequately in an ECM combat environment. Providing ECM training through fleet exercises is tremendously expensive, and is in many ways inadequate because repeated exposure to the varieties of radar jamming cannot easily be presented. A low-cost training system is needed that will provide simulation, drill and practice, and scored performance testing for both initial and refresher training.

\section{Performing Activity and Program Elememt}

This project is being performed by the Navy Personnel Research and Development Center under Program Element 63720N. Program dynamics in support of this project are illustrated in the diagram below.

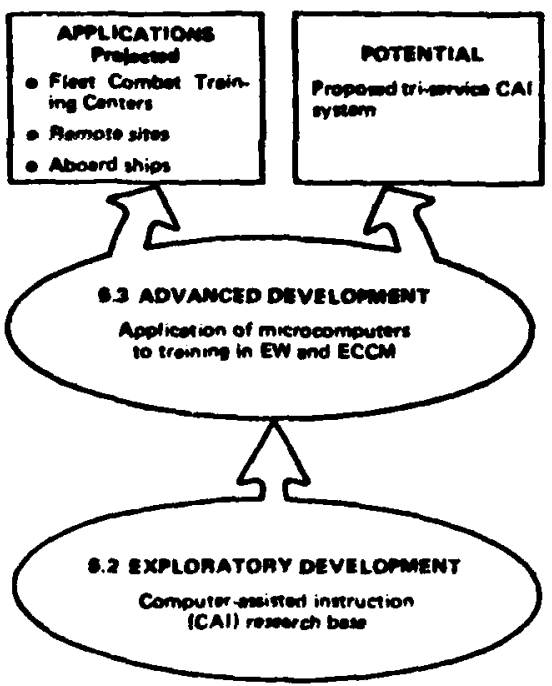

\section{Approach and Reanles}

It was determined that ECCM training could be effectively delivered through computer-essisted instruction. Accordingly, the mo: ost-effective, state-ofthe-art microprocessor-based training system, including videocassette player with random-access capebility, was selected for instructional delivery. The system uses the UCSD PASCAL languege, which was selected because of its transportability to a number of microprocessors and because of its graphics capability. Developed partly with NPRDC resources, PASCAL is a model for the DoD-sponsored ADA language being developed for future use in command-control applications within the Department of Defense.

ECCM for redar operators was selected for the first in a series of crucial training modules. This module (see figure) consists of narrated videotapes, drill and practice videotapes, and tapes for performence testing in basic radar jamming and deception and in ECCM application techniques. TEAAK Model 8510/A graphic microprocessors manage the training program. Students view videotaped presentations of actual jamming on a TV monitor and identify specific characteristics vis an input keyboand. The microprocessor then evaluates the student's entries and responds in an interactive way

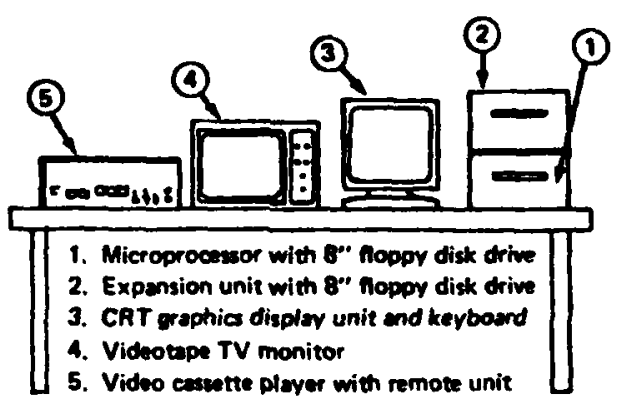

MPADC Computer Aided Insmetionel Sratem for Electronic Wurfore Training Aesouch 
through a readout screen. Trainee time and accuracy scores are automatically recorded and printed. Additional modules in advanced ECM recognition, reporting, and ECCM application techniques are in development for future test and evaluation. Also, a module in advanced threat evaluation for Electronic Warfare Technicians is being developed and evaluated for use at fleet combat training centers and at remote sites.

The module on ECM recognition and ECCM application was developed and tested at the Fleet Combat Training Center. Pacific during the period March to September 1980, using 133 fleet radar operators (Operations Specialists) enrolled in the 2-week ECCM course and in a CIC Watch Supervisor's Course. The module is an integral part of the ECCM curriculum, providing hands-on drill and practice and poiformance testing. The module resulted in substantial improvement in pretest to posttest performance scores, and produced a very favorable student response as measured by attitudinal surveys.

\section{Utilization/Technology Base Advence}

Based on the results of this effort, the Fleet Combat Training Centers, Atlantic (Virginia Beach, VA) and Pacific (San Diego, CA) have submitted resource requirements reports for budget allocations to support 15 microprocessor-based training systems each for ECCM training.

Eight microprocessor-based training systems are now being used at the Fleet Combat Training Center, Pacific to support ECCM training for fleet search radar operators in the ECCM course, CIC Watch Supervisor's Course, Advanced Warfare Specialist's Course, and an introduction to ECCM for the CIC Watch Officers' course. As of March 1981, 300 students had received training on these systems. According to the Senior Course Coordinator at FCTCP. "The Navy's training capabilities in radar jamming recognition have, until now, been severely limited. This new system enables establishment of fleet-wide proficiency standards in radar jamming recognition and countermeasure techniques." All of the present applications of this system serve as test beds for further research and development.

The modules developed by NPRDC will be provided, along with implementation assistance, to the Fleet Combat Training Center, Atlantic. Implementation assistance will also be provided to remote sites upon evaluation and conclusion of the project in the FY 83/84 timeframe.

During FY 82/83, videodisk equipment will be interfaced with the microprocessors and evaluated for effectiveness in providing rapid and realistic feedback to students during training in making ECCM fixes.

\section{Payoff/Potential}

The potential for providing timely initial or refresher training in combat skills at remote sites, and for providing simulation-not previously available-at fleet training centers and other locations, is very great. Large expenditures in fuel, manpower, and fleet exercise evolutions would be required to provide equivalent training. Each of the microprocessor-based systems, by contrast, costs under $\$ 15,000$. Also, if some of these systems were at critical remote sites, large savings in travel and in time away from duty stations could be obtained for both initial and refresher training.

\section{IMPLEMENTING THE "JOBS" PROGRAM}

\section{Need}

In late FY 79 the Navy Personnel Research and Development Center began operating a prototype training system known as JOBS, (for "Job-Oriented Basic Skills"). The objective of this prototype development effort was to see whether basic skills and knowledge could be successfully taught to a special category of personnel: lower-ability enlistees who are not qualified for " $A$ " School technical training. If JOBS was successful, these trainees could then enter " $A$ " School and perform reasonably well in comparison to fully qualified students.
As the name of the program implies, JOBS training is strongly oriented toward the actual Navy job toward the achievement of a Navy technical rating. Practice exercises are taken directly from the subject material of the technical rating, and the choice of material is focused on building the skills and knowledge required to pass "A" School courses. The underlying purpose of the JOBS program is to find a way to qualify adequate numbers of enlistees for technical ratings, in the face of declining average aptitudes among each year's recruit population. 


\section{Performing Activity and Program Eloment.}

This project was performed by the Navy Personnel Research and Development Center. R\&D funding was provided under Program Element 63720N. Additional funding support was received from the Chief of Naval Personnel and the (then) United States Office of Education of the Department of Health. Education and Welfare. Program dynamics in support of this effort are depicted in the following diagram.

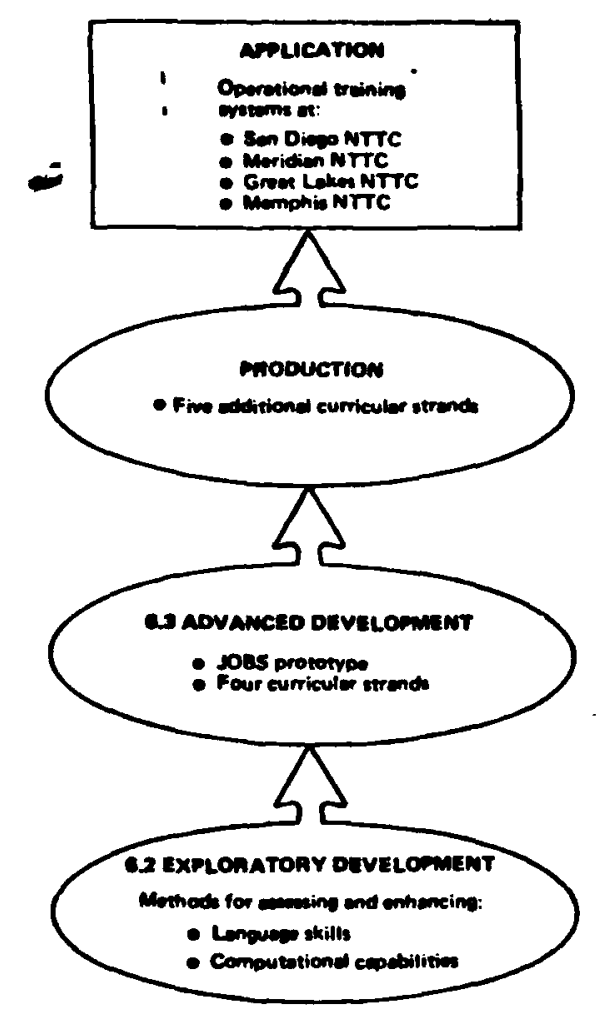

Approsech and Results

For the JOBS prototype development effort, four initial curricular strands were developed: Propulsion Engineering. Operations, Administrative/Clerical, and Electronics. The prototype training facility began operation on 30 July 1979 at the San Diego Naval Training Center. Students were selected from among a group of volunteers who were below the minimum ASVAB score levels for the follow-on technical rating. During the following year, 596 students passed through the program and went on to "A" School.
Preliminary results for all "A" Schools have shown that JOBS students graduate at a rate of 75 percent, versus 85 percent for their fully qualified "A" School counterparts. These results must be viewed in relation to the very large aptitude disedvantege that JOBS students have. For example nearly all (98 percent) of the JOBS students came from Mental Category Group IV (the lowest category), while only 10 percent of the fully qualified students were in this category. More to the point, since every JOBS student was below the maximum allowable waiver limit for entry into the fol. low-on "A" School, each JOBS graduate who successfully completes "A" School represents a gain in tech. nically trained Navy manpower that would otherwise have been lost.

\section{Utilization/Technolooy Bem Admanco}

The JOBS prototype training system operpted at the Naval Training Conter, San Diego, with a training input of 596 during the developmental stage. In October 1980, the program began transitioning to a Navy-wide training system under the operational control of the Chief of Naval Education and Training (CNET). Additional JOBS training sites were established in April 1981 at the Memphis, Meridian, and Great Lakes Training Centers. Expansion resource requirements have been identified and programmed, and five more curricular strands are scheduled for production. Planned student enroliment from all sources in FY 81 is approximately 2,900.

\section{Poyoff/Potentis}

The JOBS project directly addresses two operational problem areas. The first is to design, develop, and test a system of specialized training curricula to compensate for basic skills and knowledge deficiencies of lower-aptitude personnel entering the Navy. The second is to reduce the currently unacceptable rate of first-term attrition among General Detail Force Personnel (GENDETs). This will be accomplished by offering JOBS training as an incentive for providing trouble-free service as a GENDET. If the attrition suppression goal is met, an additional indirect benefit may be achieved-i.e., bringing a lerger percentage of enlistees to a position where they can be recommended for reenlistment. Finally, because changes in recruiting policy may produce an over-representation of racial/ethnic minorities in the GENDET force, this project has the potential for producing better minority representation across the Navy's occupational specialties. 


\section{$-$ \\ SIMULATION AND TRAINING DEVICES}

DoD defines this area of People-Related RDT\&E as follows:

"Development of cost effective training equipment and technology that produce the needed performance for operation and maintenance of military systems."

The Navy needs training devices and simulators for several purposes: to improve readiness through realistic exercise; to reduce training costs; to increase safety during practice of dangerous activities; and to reduce the destructive impact of training activities on the environment. Following Congressional guidance, several program elements have been established to accomplish these objectives.

Projects in this category include:

- Cost-Effective Avionics Maintenance Trainers

- Simulation for Advanced Submerine Tactical Training

- Low-Cost Part-Task Trainers 



\section{COST-EF FECTIVE AVIONICS MAINTENANCE TRAINERS}

\section{Need}

The increasing size, variety, and technical sophistication of Navy weapons systems, along with the continual modification to which they are subjected, means that maintenance technicians must acquire and sustain increasingly high levels of skill and knowledge. On-the-job training in the fleet is one way to upgrade skill levels; but providing OJT can be difficult, expensive, and disruptive of shipboard task performance.

- A more workable approach is through effective initial training. However, current procedures in maintenancetraining have certain drawbacks resulting from their reliance on actual operational hardware to provide hands-on training. The disadvantages of using this equipment include: (1) its high cost and resultant low availability, (2) its tendency to rapidly become obsolete, (3) inadequate instructor/student interface, (4) poor safety standards regarding trainees' use of the equipment, (5) ineffective training transfer due to a limited capability for inserting malfunctions, and (6) restricted capability for practice and repetition.

Consequentiy there is a need to revise the maintenance training approach so as to provide maximum training effectiveness at minimum overall cost, and in the shortest period of time. Simulation systems provide this kind of training when used in conjunction with Actual Equipment Trainers (AETs).

This effort focused on intermediate-level ["']" levell maintenance training, for which the AETs are test stand consoles used to check out defective system components. The objective was to fabricate an experimental model simulator for each of the following "l" level avionic subsystems: Electronic, Electromechanical, and Mechanical. The experimental simulators would then be evaluated and perfected for use as prototype trainers for " $\mid$ " level maintenance. Finally. generic procurement specifications would be generated for each subsystem, so that future aircraft introduc. tions into the fleet can be accompanied by main. tenance training simulation systems.

\section{Performing Activity and Program Eloment}

The Naval Training Equipment Center is responsible for this contract effort, which is sponsored by AIR-413. Funding is provided under Program Element 64703N. Program dynamics are depicted in the following diagram.

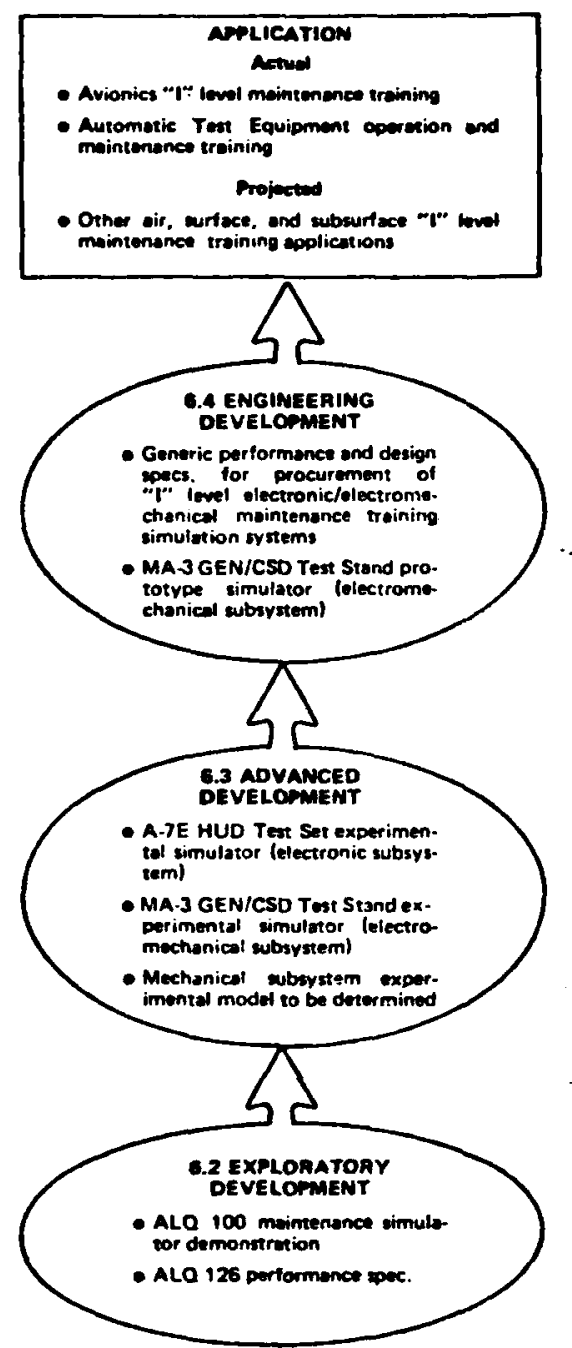

Approach and Results

Simulation can be achieved either with two-dimen. sional representations, such as photographs, TV, and graphics, or with three-dimensional fabrications which allow hands-on application with software-induced responses. The two approaches can often be combined effectively in a single system. A study of curriculum requirements and instructor recommendations revealed that the use of simulators, together with the application of computer-aided instruction (CAI), would provide individualized, self-paced training, increased 


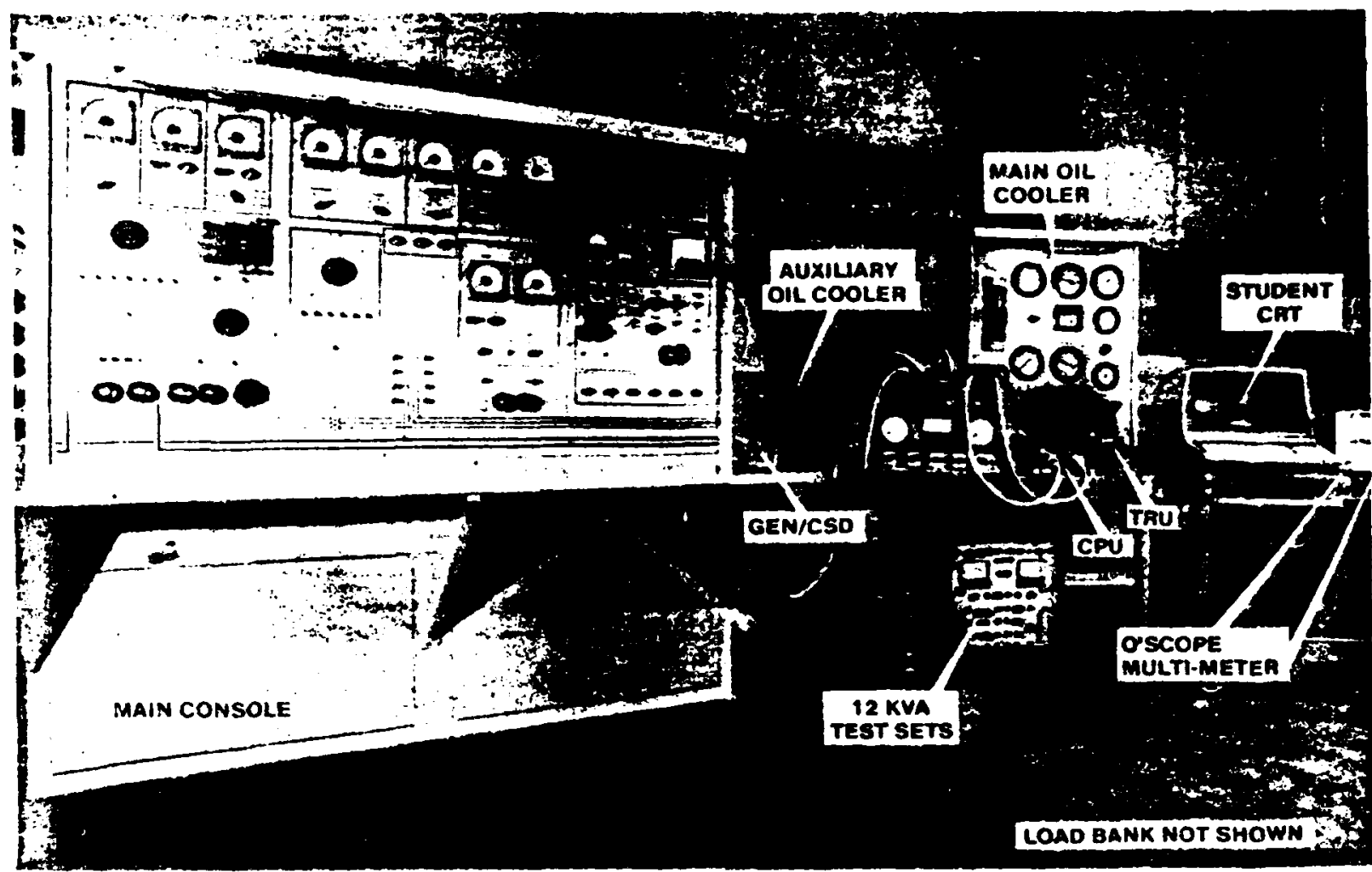

MA-3 Gemeraror/CSO Test Stend Simulator

instructor-student interaction, and consistent student evaluation capabilities.

The approach involved the development, at the 6.3 level, of experimental models which would then transition to the 6.4-level development of prototype simulated avionics maintenance trainers. These prototype simulators would then be evaluated in the training community, and procurement specifications would be generated from evaluation results.

The test bench selected for the electronic subsystem was the A.7E Head-Up Display (HUD) Test Set (see the first annual RDT\&E utilization report). At the request of Naval Air Maintenance Training Group (NAMTRAGRU), the MA.3 GEN/CSD Test Stand was selected for the electromechanical model because of the critical nature of maintenance training on this system and because of the large number of aircraft involved (A/F-18, F-14, A-6, A-7, C130, etc.). The prototype simulator test stand provides training in the complete test and check-out of aircraft power generation system components of both air-cooled and oilcooled systems. It is computer-based and offers threedimensional, hands-on training features with fault isolation and repair sequences. A modification was recently contracted to add support equipment to accommolate the AV.8A.

\section{Utilization/Technology Base Aduance}

The field evaluation of the electronic subsystem pricotype (A.7E HUD Test Set) at Naval Air Station Cecil Field showed that the system is capable of supporting procedures training. The system is presently at NTEC for further maintenance application.

The electromechanical subsystem (MA-3 Genera. tor/CSD Test Stand) is at Marine Corps Air Station Cherry Point undergoing Training Effectiveness Evalua. tion. Maintenance training procurement specifications have been developed.

Development of the experimental model simulator for the mechanical subsystem will commence in late FY 81, after an appropriate test stand has been selected.

The electronic, electromechanical, and mechanical subsystems are providing the technology base not only for aviation applications but also for surface and subsurface " 1 " level maintenance training applications.

\section{Payoff/Potential}

Benefits of the use of these simulators include reduced acquisition cost and support costs, improved safety to the user, more hands on experience, and increased practice utilizing a greater rance of sulated 
malfunctions. In addition, the trainee will benefit from realism, self-paced learning, real time feedback, and tutorial assistance from instructor-computer teams. The simulation equipment will be easy to update and easier to maintain than actual equipment.

Subsequent research efforts in this project could lead to improvements in the following training-related areas:

- Determination of optimum 2D/3D media mix in maintenance training systems
- Standardized procedures for developing func. tional specifications and conducting training effectiveness evaluations in maintenance training

- Automatic Test Equipment Simulation stressing commonality by type and group

- Inclusion of a cost-benefit prediction in the front-end analyses of maintenance training systems

- Life cycle support considerations in maintenance training simulator development.

\section{SIMULATION FOR ADVANCED SUBMARINE TACTICAL TRAINING}

\begin{abstract}
Need
Rapid advances in the technical and tactical capabilities of potential enemies have produced a corresponding increase in the sophistication of U.S. submarine weapons and weapon systems, sensors, and tactics. This technical growth has greatly complicated the submarine tactical training problem. It has not been feasible to satisfy the requirements for tactical training by at-sea exercises, because of unpredictable environmental conditions, the inability to accurately portray the potential threat, and the high operating costs and reduced availability of nuclear submarines. Submarine tactical training has been most effectively conducted in a closely controlled and easily monitored environment. Thus, the submarine forces of both the Atlantic and Pacific fleets have placed a heavy reliance on the use of shorebased Submarine Combat System Trainers (SCSTs).
\end{abstract}

Modern SCSTs are able to realistically simulate a wide variety of environmental conditions, as well as the dynamic characteristics of own-ship, targets, weapons, and other ASW platforms. However, due to the rapid increase in the capabilities of potential adversaries, and also to the sophistication and complexity of the training scenarios required for advanced tactical training in the SCSTs, the ability of tactics instructors to contral the exercises effectively is being exceeded. The instructor's task of exercising administrative and executive control over the submarine tactical training process has grown more demanding as the capabilities and complexities of submarine tactical equipment and tactics have increased. The instructor must manually control the target and weapon parameters and complex maneuvers of dynamic vehicles. In addition, he must continuously monitor and record each trainee's nerformance, reduce the performance data to an understandable format for feedback to the trainee, and evaluate trainee performance using general and elusive criteria.

Tactics training in existing SCSTs generally consists of exercising a team in a series of scenarios. The selection and control of the scenarios are left to the instructor, and are heavily dependent on the instructor's particular background and experience. Consequently, the quality of training is variable, and the effectiveness of SCST installations is highly dependent on the capabilities of each instructor.

Because of all these factors, the instructional methods and procedures required to provide this training place a heavy workload upon the instructor in existing SCSTs. The technology is available to provide assistance to the instructor in controlling training scenarios and evaluating trainee performance. There is also a need for a "smart" adversary model with inde. pendent and automatically selected actions appropriate to particular tactical training objectives. The goal of the effort reported here is to develop and integrate a number of such training assistance technologies with existing and future SCSTs to improve instructional and training effectiveness. The integrated training simu. lator/ device is known as the Submarine Advanced Reactive Tactical Training System (SMARTTS).

\section{Performing Activity and Program Element}

The SMARTTS program is the responsibility of the Naval Training Equipment Center. Funding for engineering development is being provided under Program Element $64716 \mathrm{~N}$. Program dynamics are depicted in the following diagram. 


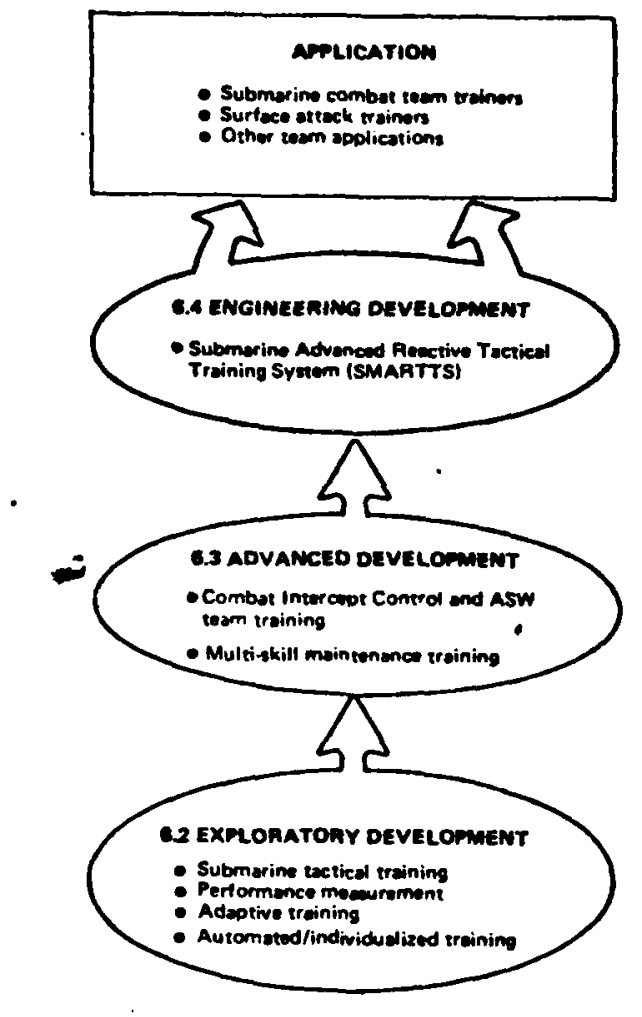

Approach and Results

A systematic approach was taken in structuring the training process and developing the necessary instructional materials. These consisted of an overall tactics training program structure with a computermanaged instruction framework, specific tactics training objectives, performance measures, identification of training techniques, specifications for the student/instructor interface, instructor and trainee guides, and other supporting material. The development of the tactics training program structure and supporting materials represented a straightforward (although complex) process tailored to the differing levels of trainees, courses, missions, and fleets. Furthermore, it considered the integration of fire control, sonar, and weapon functions.

The intelligent adversary capability (an augmented and independently acting target) has required a substantial developmental effort. It consisted of developing a target model that can take offensive and defensive action on the basis of the situational parameters, independent of the instructor. This requires the inclusion of intelligence information on enemy tactics, together with other environmental and submarine/ship systems characteristics, in the model. Instructor control of targets will be incorporated as required by the training objectives and by the particular purposes of the instructional conditions. Although this represents a substantial developmental effort, it is well within the state of the art. Initial work was accomplished by earlier efforts dealing with the design requirements and framework for this capability, in the 6.2 effort entitled "Submarine--Tactical Training System Design." The figure depicts the components of SMARTT and their functions.
SIMULATION SUBSYSTEM

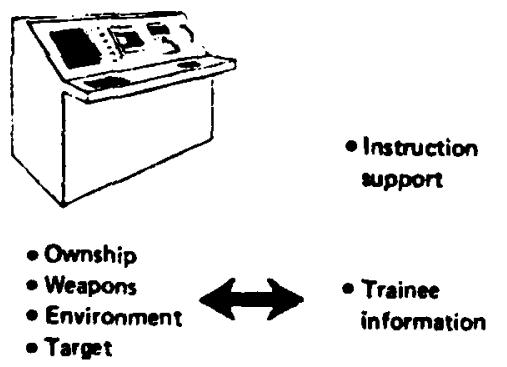

- Training system managernent

\section{TAAINING SUESYSTEM}

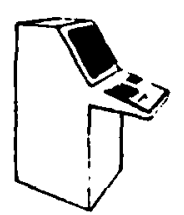

INSTAUCTOR'S CONSOLE

- Exercise generation

- Porformince evaluation

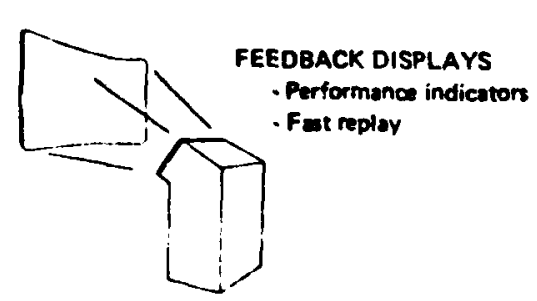

- Coordination

- Curriaulum materials

- Training effectiveness evaluation

SMARTTS Training Device 
The preprototype and follow-on SMARTTS development will be compatible with the existing tactical and simulation software of SCSTs. Capabilities for the automated control of simulated targets and the measurement of tactical team performance will be developed and implemented in existing and future Submarine Combat System Trainers. The five existing Trainers are Devices 21A37, New London, CT; 21A38, Pearl Harbor, HI: 21A39, Charleston, SC; 21A43, San Diego, CA; and 21A41, Norfolk, VA.

The plan for implementing SMARTTS consists of four phases. The first three phases involve research and development. They are: (1) establishment of training requirements; (2) preprototype development and implementation; and (3) RDT\&E. Work has been accomplishedin each of these three phases to varying degrees. Phase One has been completed. The development and implementation of the preprototype (Phase Two) was approximately $\mathbf{4 0}$ percent complete at the time of writing, with site acceptance testing scheduled for December 1981. The initial control, or baseline, data of system effectiveness to be used in the Phase Three RDT\&E has been collected at Device 21A41, where SMARTTS will be installed and evaluated. The fourth and final phase of the SMARTTS program will be the upgrading of the preprototype to production levels and the deployment of SMARTTS to the remaining sites.

\section{Utilization/Technology Base Advance}

This effort will produce automated control of simulated targets and measurement of tactical team performance capability for implementation in five existing trainers and in future Sutmarine Combat System Trainers. Levels of training presented by these various SCSTs will include basic through prospective commanding officer training. Direct benefits will be gained by providing instructors with a support system that enables them to direct more of their time toward training, rather than toward maintaining the exercise itself.

Additionally, this project will provide objective performance indicators which are not currently available. This new objectivity will enhance the training process through improved diagnostic capability and better remediation. Research products include the further evaluation of adaptive feedback and advanced instructional technologies; for example, it will demonstrate the feasibility of developing a generic instructional model for which software could be adaptable according to the training need.

\section{Payoff/Potential}

The improved effectiveness and capability of shorebased training will produce cost benefits through savings in fuel and operating costs that result from the reduced amount of at-sea training needed for basic skill acquisition. Furthermore, having more efficient training that produces a higher-skilled student with no increase in training time is of considerable benefit in light of the reduced manpower leveis presently being experienced by the Navy. Another potential operational costs payoff is that SMARTTS will directly contribute to combat readiness by allowing for shorebased proficiency training.

\section{LOW-COST PART-TASK TRAINERS}

\section{Need}

A large proportion of aviation training is con. ducted with a focus on specific mission elements (e.g., navigation, cockpit procedures, and weapon system familiarization). This type of training is known as part-task training. Many part-task applications in aviation training are currently being conducted in full-mission simulators such as Operational Flight Trainers (OFTs) and Weapon System Trainers (WSTs). These sophisticated simulation systems are designed to be utilized for a training scope encompassing all capabilities of the aircraft being simulated (taxi, takeoff, tactical flight, instrument approach, and landingl. Attempting to train in any single mission element of this overall capability detracts from the most effective utilization of these trainers. Moreover, continually increasing costs of full-mission simulators have made it difficult to procure them in sufficient numbers to satisfy even the broader-scope training requirements for which they are intended.

The preferred approach is to use part-task trainers to provide both initial skills training and refresher training in specific mission elements. But traditional practice in the development of part-task trainers has resulted in devices that simulate more functions of the actual weapon systern than are actually necessary. Also, there has been an excessive emphasis on the fidelity of simulation. These two factors have made part-task trainers unnecessarily expensive.

There is a need for low-cost part-task trainers that can: (1) provide for mission element training and practice without encroaching on training time available 
on full mission simulators; and $(2)$ be procured in sufficient numbers and types to allow for wider distribution in the fleet and for the satisfaction of necessary training requirements.

\section{Performing Activity and Progrem Element}

This development was initiated at the request of the Naval Air Systems Command (AIR-413), and was carried out by the Human Factors Laboratory at the Naval Training Equipment Center. The training analysis and evaluation phases were funded under Program Element $62757 \mathrm{~N}$. The hardware procurement is funded by AIR-413. Program dynamics ' in support of this effort are depicted in the following diagram.

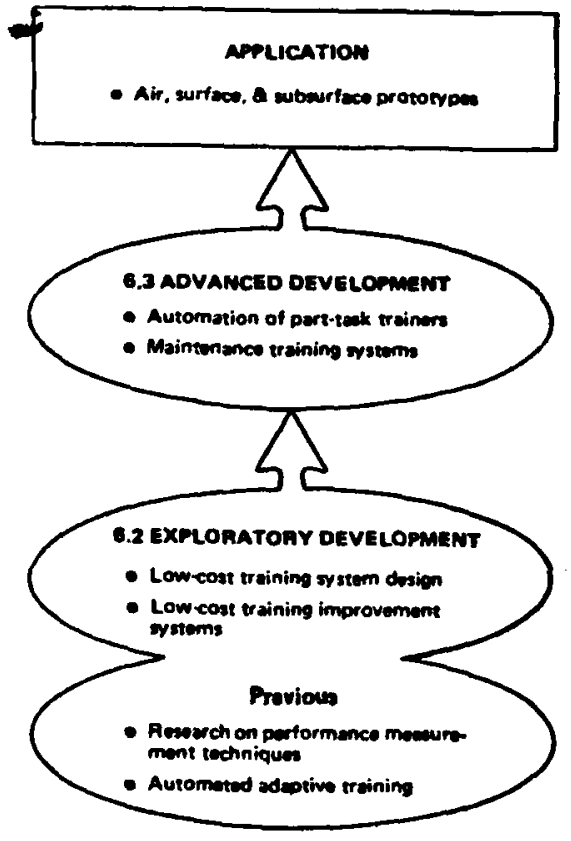

\section{Approsech and Reaults}

Current technology was applied to devolop a relatively inexpensive part-task trainer. The specific application was for a Cockpit Procedures Trainer (CPT) simulating the SH-3H aircraft. This dovico was developed experimentally using selected low-cost approaches to aircrew training in normal and emer. gency procedures.

The complete system includes three major components:

- A cockpit with controls and displays representing those of the actual aircraft

- An instructor/student station from which problems are initiated, trainee performance is monitored, and data retrieval and computer programming are controlled

- A computer system that activates and coordinates all trainer functions.

The simulated cockpit contains functional components which are similar to those of the aircraft in terms of position, size, appearance, control feel, and operating characteristics (see figures). In order to present the complete cockpit layout, instrumentation and panels that are not essential to the required training are displayed as nonfunctional mockups.

The instructor/student station is designed to be used by another student acting as the instructor. His functions will include setting up tasks as well as aiding and evaluating trainee performance. The requirement for formal instructors is thus eliminated. The station contains keyboard controls and CRT displays located for convenient operation and observation. It is even possible for the student trainee to set up a task and monitor his own performance using these equipments. Instructional capabilities of the system include

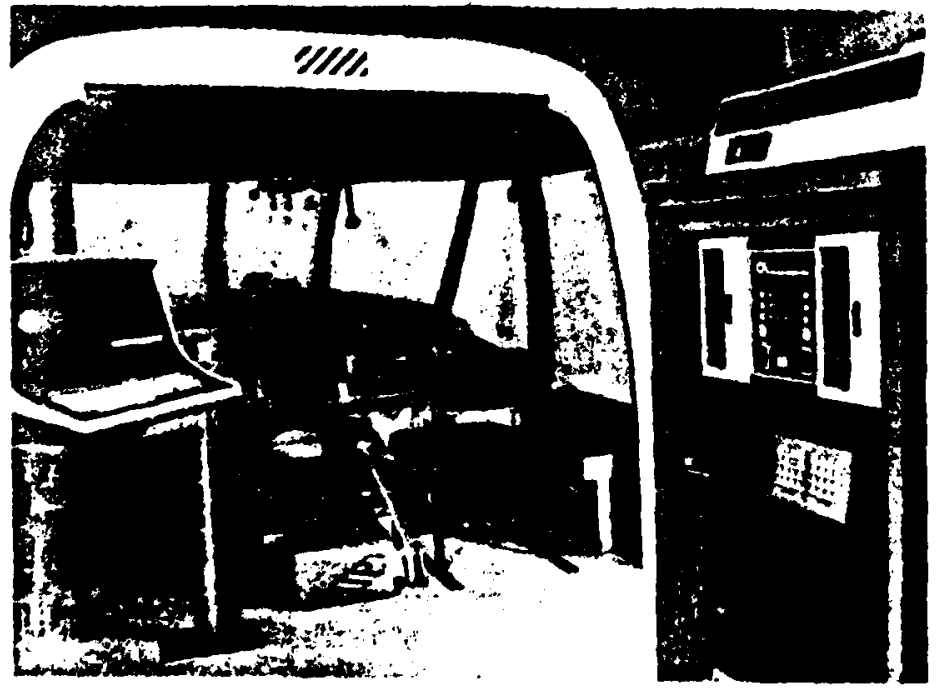

interior of the SH-3H Low Cost CPT

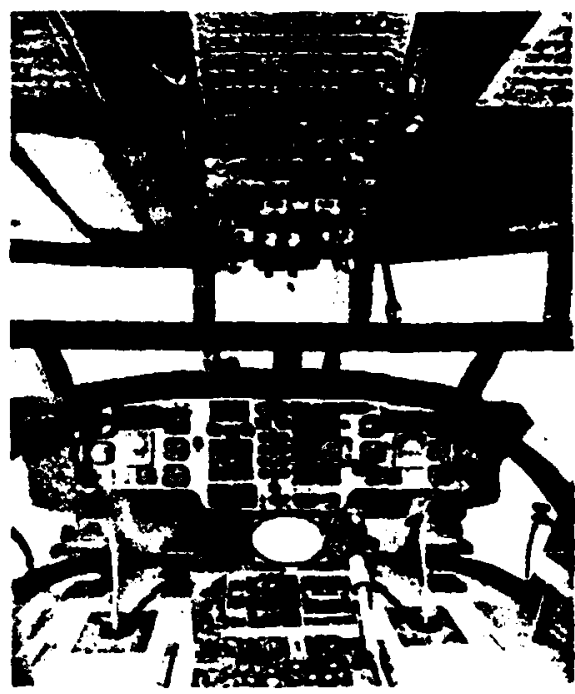

instrumencetion and Controts of the SH-3H Low Cost COT 
11 normal and 33 emergency NATOPS procedures. Additionally, over 100 aircraft malfunctions can be presented.

The computer system consists of a microprocessor with dual floppy disks, an interconnect with the instructor/student station CAT, and a line printer for recordkeeping.

The cost-saving design features that were employed include the following:

- Fabricating to best commercial practices (rather than adhering to the more stringent Government MIL Standards).

- Limiting fidelity to only those areas that are necessary to accomplish required training (for example, approximate cockpit configurations, chairs vs. cockpit seats, photographs vs. actual panels, dynamic instrument presentations only as required, malfunctions present on set cues but not progressive degradation).

- Eliminating unnecessary redundancies (for example, simulating malfunctions on only one engine rather than on all engines).

By means of such techniques the development cost of this SH-3H CPT was kept to approximately one-fifth that required for a conventionally designed counter. part. Experimental comparison of the training capability of the low-cost CPT with that of the conventional SH-3D CPT (Device 2C44) was carried out at NAS Jacksonville, Florida. The evaluation showed that students performed equally well in the low-cost CPT (and, subsequently, in the actual aircraft) as did those trained in the conventional CPT. Further evaluation of the trainer is presently in progress at NAS North Island.

\section{Utilization/Technology Base Advạnce}

All Naval Aviation training activities will use the low-cost CPT developed here. The same concepts involved in the development of the SH-3H CPT have now been used to develop a low-cost part-task trainer for the EA-3B aircraft. This trainer will satisfy all CPT training requirements for both the pilot and the bombardier/navigator. Additional capabilities will provide for training in instrument flight and navigation procedures. Included in the development is a low-cost visual system intended to provide training in day/night carrier and field landings. The cost of this part-task trainer is approximately one-tenth the cost of a tradi. tional trainer with similar capabilities. Fleet evaluation of the trainer began early in FY 81 at VAQ 33, Key West, Florida.

There are tentative plans to utilize this low-cost technology in all future procurement of CPTs. The concepts and techniques employed in the development of these low:cost part-task trainers offer the potential for expansion into other areas, including maintenance training and surface/subsurface training applications.

\section{Payoff/Potential}

The most significant benefit emerging from the development of the SH.3H CPT is the capability to procure larger numbers of these less expensive part-task trainers for wider distribution throughout the aviation community. As a result, full-mission simulators can be utilized more efficiently, which will improve readiness.

The lower development costs are attributable largely to cost-cutting design choices. For example, by fabricating to best commercial practices, 30 percent savings on materials and $\mathbf{2 5}$ percent savings on docu. mentation costs can be realized. By providing only essential fidelity, $\mathbf{4 0}$ percent cost savings are possible. Elimination of redundancies offers an additional 5 percent potential savings.

Using these design concepts the development cost of the SH-3H CPT was $\$ 325 K$, compared to approximately $\$ 1.5 \mathrm{M}$ for the conventional SH.3D CPT. The EA-3B part-task trainer will cost $\$ 600 \mathrm{~K}$ compared with millions required for a conventional device possessing the same training capabilities.

Additional benefits include reduced instructor requirements, automated scoring and feedback. less trainer development time, and reduced maintenance requirements.

Should these experimental low-cost trainers prove to be as effective as anticipated, broad application areas exist in air, surface, and subsurface communities, with potential cost savings of millions of dollars compared with the increasingly expensive traditional trainers. 



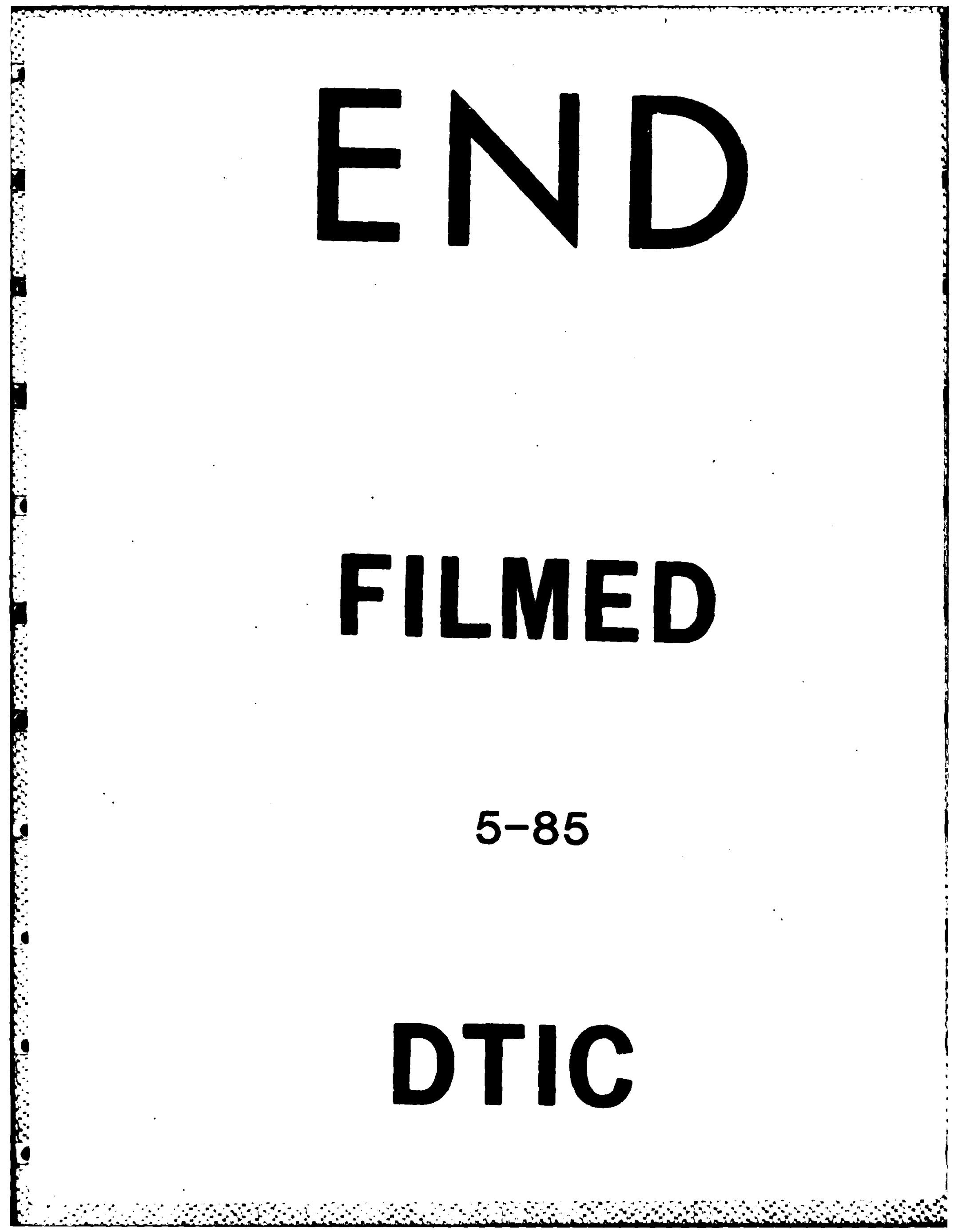

